\title{
Free-Riding for Future: Field Experimental Evidence of Strategic Substitutability in Climate Protest*
}

\author{
Johannes Jarke-Neuert $^{\dagger} \quad$ Grischa Perino $^{\ddagger} \quad$ Henrike Schwickert $^{\S}$
}

\begin{abstract}
We test the hypothesis that protest participation decisions in an adult population of potential climate protesters are interdependent. Subjects $(n=1,510)$ from the four largest German cities were recruited two weeks before protest date. We measured participation (ex post) and beliefs about the other subjects' participation (ex ante) in an online survey, used a randomized informational intervention to induce exogenous variance in beliefs, and estimated the causal effect of a change in belief on the probability of participation using a control function approach. Participation decisions are found to be strategic substitutes: a one percentage-point increase of belief causes a .67 percentage-point decrease in the probability of participation in the average subject.
\end{abstract}

Keywords: collective action; social movement; protest; environment; climate action; strategic interaction; experiment; causal mediation; instrumental variable regression

JEL classification: C93, D71, D74, D83, Q54

\section{Introduction}

Political protest is surging at an historically unprecedented level (Weibel, 2015; Almeida, 2019b; Brannen et al., 2020), catalyzed by social media and other digital applications (Jost et al., 2018; Freelon et al., 2020). As protest movements play a key role in the process of social change (Tilly, 1978; Acemoglu and Robinson, 2006; Markoff, 2014; Chase-Dunn and Almeida, 2020), an understanding of the former furthers our understanding of the latter.

The intellectual challenge has attracted great interest in various disciplines (see Section 6 for a brief discussion). Economic and game theoretic reasoning has contributed the "strategic mobilization hypothesis" (Jarke-Neuert, 2021): individual protest participation decisions are rational and interdependent, and so beliefs about others' behavior play a key role in protest dynamics. However, albeit the hypothesis traces back to at least the 1950s, it has not been credibly tested empirically until very recently—with mixed results (Cantoni et al., 2019; Manacorda and Tesei, 2020; González, 2020)— and never in one of the most prominent movements of our time: climate protest. This is what we do in the present paper.

\footnotetext{
${ }^{*}$ The research for this article has been funded by the Deutsche Forschungsgemeinschaft (DFG, German Research Foundation) under Germany's Excellence Strategy, cluster EXC 2037 “CLICCS: Climate, Climatic Change, and Society" (project number: 390683824), and contributes to the Center for Earth System Research and Sustainability (CEN) of Universität Hamburg. Henrike Schwickert gratefully acknowledges funding by the Konrad-Adenauer-Foundation. Data were collected in collaboration with the Munich office of The Kantar Group Ltd. (London, UK) under commercial contract. The study was pre-registered in the Randomized Controlled Trial Registry of the American Economic Association under code AEARCTR0004583. All data and materials of the study are freely available online at the Open Science Framework (OSF) under DOI 10.17605/OSFIO/Z2EWS. Thanks to Jane Torbert for preparation of the questionnaire transcript. The authors declare no conflicts of interest.

${ }^{\dagger}$ Center of Earth System Research and Sustainability (CEN), University of Hamburg. Corresponding author. Mail: Grindelberg 5, 20144 Hamburg, Germany. Phone: +49 04042838 8369. E-mail: johannes.jarke-neuert@uni-hamburg.de.

${ }^{\ddagger}$ Department of Socioeconomics and Center of Earth System Research and Sustainability (CEN), University of Hamburg.

${ }^{\S}$ Department of Socioeconomics, University of Hamburg.
} 
Climate change is the realm in which deep social change is most desperately needed. The scientific facts are on the table (Masson-Delmotte et al., 2021; Sognnaes et al., 2021), and a global majority expresses support for change (Flynn et al., 2021). Yet, it is not happening at a magnitude that is even close to enough for prevention of catastrophe (Ripple et al., 2021; Stammer et al., 2021; Liu and Raftery, 2021). It is the youth that is taking worry, anger, and frustration about the state of matters to the streets (Henry et al., 2020; de Moor et al., 2020), engaging in "do-it-ourselves politics" (Pickard, 2019). ${ }^{1}$ Youth-driven climate protests emerged around UN Climate Summits in the 2000s and gained significant momentum since the global "Rise for Climate" campaign and the birth of the "Fridays for Future" movement (FFF) in 2018 (Almeida, 2019a; Beckh and Limmer, 2022). Other movements (like "Extinction Rebellion" or the US-based "Sunrise Movement") and a series of so-called "Global Climate Strikes" followed in 2019. The latter's third edition in September was the largest climate protest event in history, mobilizing reportedly 7.6 million in more than 6,000 events spread across 185 countries (Chase-Dunn and Almeida, 2020). This event is the context of our study.

We exploited the unique opportunity that adults were explicitly invited to the Climate Strike events for the first time. The climate protest movement can apparently mobilize large crowds of youth, and there is a growing body of evidence on the motivational structure to turn to the streets (see Section 6), but much less is known about the mobilization potential and motivational structure in the older cohorts of the population. However, this potential is a key driver of the impact capacity of the movement as a whole, as the adult population is clearly pivotal for creating sufficient pressure in the political process (see note 1).

We recruited more than 1,500 adults in the four largest German cities-Berlin, Hamburg, Munich, and Cologne-two weeks before publicly announced local protest events that happened simultaneously on September 20, 2019. We measured participation (ex post) and beliefs about the other subjects' participation (ex ante) with an online survey, used a randomized informational intervention to induce exogenous variance in beliefs, and estimated the causal effect of a change in belief on the probability of participation using a control function approach. The data clearly support the strategic mobilization hypothesis, and we find participation decisions to be strategic substitutes.

The remainder of the paper is structured as follows. In Section 2 we formulate the testable hypothesis. The data and the collection procedures are desribed in Section 3. Section 4 explains the statistical inference methods. The empirical results and evidence supporting the identifying assumptions are presented in Section 5. Section 6 discusses the contribution to the literature, and in Section 7 we conclude by daring an outlook regarding the future of climate protest, and by suggesting avenues for further research.

\section{Hypothesis}

We draw on a micro-founded parametric model of political protest mobilization (Jarke-Neuert, 2021), which explains the mean participation probability in a population of potential protesters as a function of preferences and beliefs. Specifically, the conditional probability of protest participation is assumed to be governed by

$$
\operatorname{Pr}(a=1 \mid b, \boldsymbol{x})=\Phi(\alpha+\beta \cdot b+\boldsymbol{x} \cdot \boldsymbol{\gamma})
$$

where $a \in\{0,1\}$ indicates protest participation, $b \in[0,1]$ is the probabilistic belief regarding the participation probability of an average other potential participant, $\boldsymbol{x}=\left(x_{1}, \ldots, x_{k}\right)$ is a vector of optional covariates, $\Phi$ is the standard normal cumulative distribution function, and $\left(\alpha, \beta, \gamma_{1}, \ldots, \gamma_{k}\right) \in \mathbb{R}^{k+2}$ are fixed parameters. Parameter $\beta$ captures the interdependent ("strategic") component of the participation decision, with values $\beta>0$ indicating strategic complementarity (a potential participant's

\footnotetext{
${ }^{1}$ Young cohorts are affected by the effects of global warming mostly, while being under-represented and lacking agency in the formal political and governmental institutions (Norris, 2002; Martin, 2012; Sloam, 2013, 2016; Grasso, 2016), such that the incentive to protest is strong (Weiss, 2020). Furthermore, there are powerful social barriers in the way of effective climate action (Bernauer, 2013; Gifford et al., 2011), and at least some are related to the age structure at key loci of decisionmaking (Aldy et al., 2012; Rickards et al., 2014; Andor et al., 2019). Not surprisingly, inter-generational justice is one of the key themes in climate protest (Holmberg and Alvinius, 2019; Hayes and O'Neill, 2021; von Zabern and Tulloch, 2021)
} 
marginal utility of participation is increasing in expected protest size) and $\beta<0$ indicating strategic substitutability (marginal utility is decreasing in expected protest size). ${ }^{2}$ The basic aim of the present study is a test of hypothesis

$$
\mathrm{H}_{0}: \beta=0 \text { vs. } \mathrm{H}_{1}: \beta \neq 0 .
$$

We also want to estimate the sign and the magnitude of the marginal effect

$$
\frac{\partial \operatorname{Pr}(a=1 \mid b, \boldsymbol{x})}{\partial b}=\varphi(\alpha+\beta \cdot b+\boldsymbol{x} \cdot \boldsymbol{\gamma}) \cdot \boldsymbol{\beta}
$$

evaluated at a suitable value of belief and averaged over $\boldsymbol{x}$ ( $\varphi$ denoting the standard normal density), the average partial effect (APE) of a change of belief on the probability of participation.

In principle, the parameters $(\alpha, \beta, \gamma)$ and their asymptotic variance can be estimated from any dataset containing paired (independent and identically distributed) observations of participation decisions and beliefs by (conditional) maximum likelihood estimation (Wooldridge, 2010, pp. 389). However, beliefs are not only difficult to measure (as they are cognitive constructs), but they are also influenced by a myriad of uncontrollable and unobservable (hence not included in $\boldsymbol{x}$ ) events, such that estimates of the parameters based on purely observational data would likely be polluted by spurious correlation or masked causation. ${ }^{3}$ Consequently, we could falsely reject or falsely not reject $\mathrm{H}_{0}$. We therefore resort to a carefully designed randomized controlled trial design involving an information provision intervention (section 3), and advanced methods of data analysis (section 4).

\section{Data}

The study was built around the so-called Third Global Climate Strike on September 20, 2019, a collection of protest events at many locations around the globe that were coordinated with respect to date but organized locally by climate activist volunteers (typically FFF activists).

We focused on the events in four major German cities-Berlin, Hamburg, Munich, and Cologneto exploit two critical features. ${ }^{4}$ First, they were not spontaneous, but public calls with a specific date, time, and location were circulated by the local FFF organizers weeks ahead of time via various means (flyers, stickers, social media, conventional media, etc.). ${ }^{5}$ This was essential for planning a study around the events. Second, adults at all ages were explicitly invited by the organizers to participate. This feature was new to the Climate Strike movement that has previously been driven by youth (de Moor et al., 2020), and it provided not only a unique opportunity to study "a game in the making" within a new segment of the population, but the limited experience of those new "players" with the "game" granted us scope for an informational intervention, to be described in section 3.3. Before that we expose the sampling procedures in Section 3.1, and show in Section 3.2 how the variables of the participation model have been measured.

\subsection{Sampling}

Data were collected in collaboration with the Munich office of The Kantar Group Ltd. (London, UK) under commercial contract. The company administers local opt-in online panels of volunteers (typically used for market research) in each of the four subject cities.

\footnotetext{
${ }^{2}$ The connection to the conventional definitions of strategic complementarity and substitutability, respectively, in terms of marginal utility is made explicit in Jarke-Neuert (2021) via the latent variable formulation of (1), which is derived from a simple random utility model of decision-making. Mild and plausible normality assumptions about the distribution of random utilities justify the probit link function. It also follows that parameter $\alpha$ and the latent variable model error captures motivations to participate (or not) that are independent from turnout (e. g. moral duty, see Section 6 for evidence).

${ }^{3}$ Technically, if beliefs are not independent from the latent variable model error (i. e. $b$ is not exogenous), which is likely the case with purely observational data, then the conditional densities on which the likelihood maximization problem is defined will be misspecified, and estimates would hence be inconsistent. See Wooldridge (2010, pp. 391) for details.

${ }^{4}$ The four cities are the largest (in terms of population) in Germany. Population sizes, gender distributions, and age-class distributions as of end 2019 from official census records are provided in Table 11 in the Appendix.

${ }^{5}$ The events were scheduled on 12pm at Brandenburger Tor in Berlin, 12pm at Jungfernstieg in Hamburg, 12pm at Königsplatz in Munich, and 1lam at Hans-Böckler-Platz in Cologne.
} 
Table 1: Sample breakdown by location and survey.

\begin{tabular}{lccccr}
\hline & Berlin & Hamburg & Munich & Cologne & Overall \\
\hline 1st survey & $848(.3294)$ & $651(.2529)$ & $490(.1904)$ & $585(.2273)$ & 2,574 \\
2nd survey & $610(.3246)$ & $481(.2560)$ & $363(.1932)$ & $425(.2262)$ & 1,879 \\
3rd survey & $490(.3245)$ & $399(.2642)$ & $280(.1854)$ & $341(.2258)$ & 1,510 \\
\hline
\end{tabular}

Table notes: Listed are the counts of subjects that completed the respective survey in the respective location class, with row percentages in parentheses. Kruskal-Wallis equality-of-populations rank tests do not reject the hypothesis that sample attrition between the first and the second survey $\left(\chi^{2}(3)=1.075\right.$ with ties, $\left.p=.7831\right)$ and between the second and the third $\left(\chi^{2}(3)=2.623\right.$ with ties, $\left.p=.4534\right)$ is equal across locations. Overall fractional attrition rates are .270 for the second survey (relative to the first) and .196 for the third survey (relative to the second).

Invitations to participate in a scientific study on "environmental and climate protection matters" involving three sequential surveys were sent out to registered panelists aged between 18 and 69 by e-mail on September 6, 2019. They were informed that they would be compensated financially for each completed survey according to Kantar's default lump-sum rates, ${ }^{6}$ plus a bonus for completing all three surveys. The full invitation text is provided in the OSF online materials (Jarke-Neuert et al., 2021).

Panelists could accept the invitation and complete the first survey between September 6 (Friday) and September 11 (Wednesday) at midnight, local time. A total of 2,576 subjects accepted the invitation, two dropped out during the first survey. Those 2,574 subjects who completed the first survey were invited to the second survey, which was open between September 16 (Monday) and September 20 (Friday) at noon, local time. The 1,879 panelists that completed the second survey were invited to the third survey that was fielded between December 5 (Thursday) and December 16 (Monday). ${ }^{7} \mathrm{~A}$ total of 1,510 subjects completed all three surveys. A breakdown of the sampling process by location is shown in Table 1. The sample in the bottom row, comprising all subjects that completed all three surveys, enters the data analysis. Sample breakdowns by location, gender and age are provided in the Appendix in Table $12 .^{8}$

\subsection{Measurement instruments}

In the three surveys we measured the variables of the model described equation (1) plus additional data. A schematic overview is shown in Figure 1. At the beginning of the first questionnaire, respondents were briefly introduced to the subject matter in objective and neutral language, and confronted with the public call applicable to their city of residence. It was also explained to them that people between 18 and 69 years living in the same city are surveyed, and that this group approximates the structure of the local population. We describe measurement of the key variables here, the

\footnotetext{
${ }^{6}$ We deliberately opted against response-conditioned incentives to avoid undesirable side-effects. The data collection contractor (Kantar) informed us that they have established a "code of honor" for truthfulness with their respondents, and response-conditioned incentives would undermine this code and make non-truthfulness salient in the first place. This is supported by evidence (Gritz, 2004; Kamenica, 2012). There is also evidence that scoring rules for belief elicitation can adversely affect accuracy and induce hedging, although the problem appears to hinge on specific details of implementation (Gächter and Renner, 2010; Blanco et al., 2010; Armantier and Treich, 2013; Schlag et al., 2015).

${ }^{7}$ The third survey has been originally planned for the period between September 21 and October 1 but had to be postponed due to technical problems of the data collection contractor (Kantar). Since the single survey instrument used for the experiment was a simple fact question about participation in the local protest event (see section 3.2), it is unlikely that the delay caused any kind of problem. We used the opportunity to also elicit participation decisions for the so-called Fourth Global Climate Strike (November 28, 2019) for explorative purposes.

${ }^{8}$ Probability-expected sampling frequencies based on the gender and age distributions in the local populations of inhabitants are listed in Table 13 in the Appendix. They show that the oldest age group (65 or older) is under-represented somewhat in our sample, which is to be expected by the sampling restriction (69 or younger) and from online access panels in general (Blasius and Brandt, 2010). To compensate, the next younger age group (50-65) is over-sampled a bit. Overall, the sample approximates the local populations acceptably, although we emphasize that representativeness was not an objective for this study.
} 
Table 2: Measured behavior with regard to the climate protest on September 20, 2019.

\begin{tabular}{lrrrrr}
\hline & Berlin & Hamburg & Munich & Cologne & Overall \\
\hline Q25.1 Local participant $(a=1)$ & .0918 & .1128 & .1036 & .1378 & .1099 \\
Q25.2 Local observer & .0735 & .1153 & .1000 & .0880 & .0927 \\
Q25.3 Local counter-protester & .0000 & .0000 & .0000 & .0029 & .0007 \\
Q25.4 Participant elsewhere & .0245 & .0401 & .0321 & .0411 & .0338 \\
Q25.5 Absent & .8102 & .7318 & .7643 & .7302 & .7629 \\
\hline
\end{tabular}

Table notes: Listed are the empirical distributions of responses to survey instrument Q25 in the third survey, which is equal to the distributions in the final sample (subjects that completed all three surveys, the bottom row of Table 1), in the form of relative frequencies. A Kruskal-Wallis equality-of-populations rank test rejects equality of distributions across locations at a five percent level of significance $\left(\chi^{2}(3)=9.647\right.$ with ties, $\left.p=.0218\right)$.

full questionnaires in German (original) and English (transcript) are available in the OSF online materials (Jarke-Neuert et al., 2021). ${ }^{9}$

The participation indicator $a \in\{0,1\}$ was measured in the third survey with the following fivepoint nominal-scale instrument (Q25 in the questionnaire): ${ }^{10}$

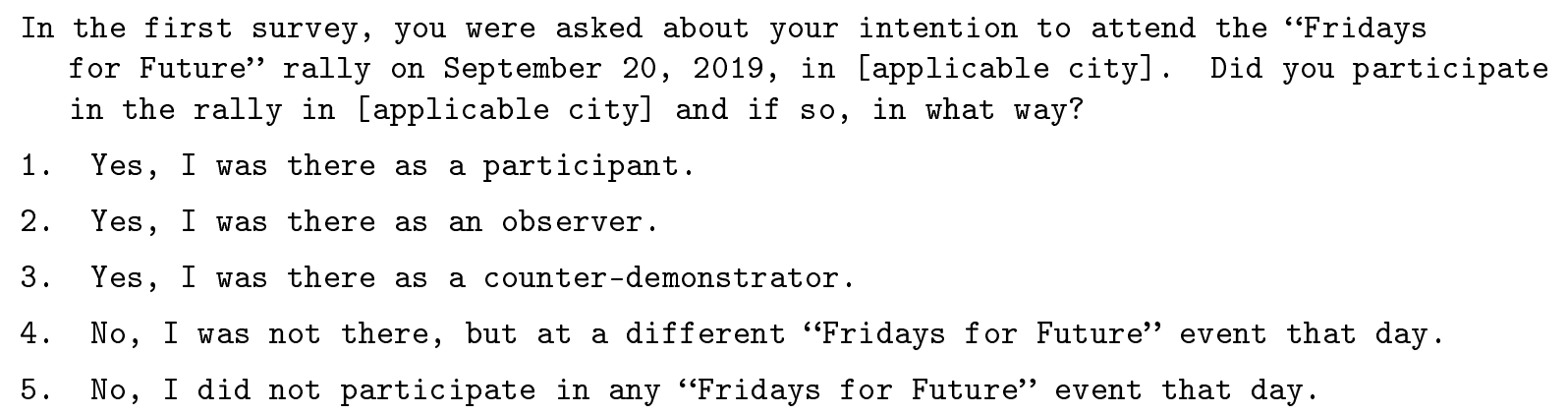

The participation indicator was set to $a=1$ for subjects that selected response 1 , and to $a=0$ otherwise. The distributions of responses at each location and in the pooled sample is shown in Table 2 .

The belief $b$ was elicited (post-intervention) in the second survey, a pre-intervention belief that helps in controlling for the endogeneity of $b$ (see Section 4) — to be denoted $b^{\prime}$ —-was measured in the first survey. The latter was elicited with the following input-box instrument (Q13 in the questionnaire):
What do you think - what percentage of all survey respondents will actually participate in the "Fridays for Future" rally on September 20, 2019, in [applicable city]? There is no right or wrong answer, we are interested in your personal assessment. I estimate that of all survey respondents, --_.- percent will actually participate.

The post-intervention belief instrument (Q19) in the second survey was essentially identical, the only difference was an introductory sentence that reminded subjects of their own previous response in Q13, and then continued to explain:

\footnotetext{
${ }^{9}$ There are many additional socio-demographic and opinion items and a finer treatment (separating a "younger" and an "older" age class) in the questionnaire (and the dataset), which we donate to the community for further research. We devoted great care in asking the questions in a sequence that does not pollute our key instruments.

${ }^{10}$ We used the five-point distinction instead of asking a binary question to avoid misunderstandings of what "participating" means. We wanted be able to distinguish between actual participants (response 1) and people that happened to be there for other reasons (responses 2 and 3). Since there were events at many locations on the same day, we also wanted to distinguish participants in the local event (response 1) and other events (response 4). The questionnaire contained a number of additional questions for explorative purposes. The questionnaire also referred to "Fridays for Future rally" because the movement is commonly known under this term in Germany, and the call was published under that label.
} 
Table 3: Summary of pre-intervention beliefs regarding others' participation $\left(b^{\prime}\right)$ in the climate protest on September 20, 2019.

\begin{tabular}{llllll}
\hline & Berlin & Hamburg & Munich & Cologne & Overall \\
\hline 5-percentile & $.020(.020)$ & $.020(.020)$ & $.020(.020)$ & $.020(.020)$ & $.020(.020)$ \\
25-percentile & $.100(.100)$ & $.100(.100)$ & $.080(.080)$ & $.090(.100)$ & $.100(.100)$ \\
Median & $.200(.200)$ & $.200(.200)$ & $.200(.200)$ & $.200(.200)$ & $.200(.200)$ \\
75 -percentile & $.400(.400)$ & $.350(.400)$ & $.350(.360)$ & $.400(.400)$ & $.370(.400)$ \\
95-percentile & $.700(.700)$ & $.670(.660)$ & $.600(.650)$ & $.650(.700)$ & $.660(.700)$ \\
\hline Mean & $.2600(.2698)$ & $.2473(.2570)$ & $.2381(.2429)$ & $.2481(.2615)$ & $.2499(.2596)$ \\
Standard deviation & $.2195(.2260)$ & $.1954(.2025)$ & $.1917(.2012)$ & $.2080(.2217)$ & $.2056(.2148)$ \\
\hline
\end{tabular}

Table notes: Listed are statistics of the empirical distributions in the final sample (subjects that completed all three surveys, the bottom row of Table 1), with statistics of the distributions in the intermediate first survey sample (including subjects that completed only the first or the first two surveys, the top row of Table 1) in parentheses. Two-sample Kolmogorov-Smirnov tests do not reject equality of distribution functions in the final sample and the class of dropouts (Berlin $D=.0774$, exact $p=.157$; Hamburg $D=.0894$, exact $p=.158$; Munich $D=.0429$, exact $p=.974$; Cologne $D=.0661$, exact $p=.535)$. A Kruskal-Wallis equality-of-populations rank test does not reject equality of distributions across locations $\left(\chi^{2}(3)=1.109\right.$ with ties, $\left.p=.7748\right)$. A Shapiro-Wilk test rejects normality $(z=11.181, p=.0000)$. A maximum likelihood fit to a beta distribition yields a shape parameter estimate of .9805 (SEE .0317, $p=.000$ ) and a scale parameter estimate of 2.8988 (SEE .1093, $p=.000$ ) at $\log \mathscr{L}=631.82672$. A one-sample Kolmogorov-Smirnov test does not reject equality between this theoretical distribution and the empirical distribution $(D=.0917, p=.000)$.

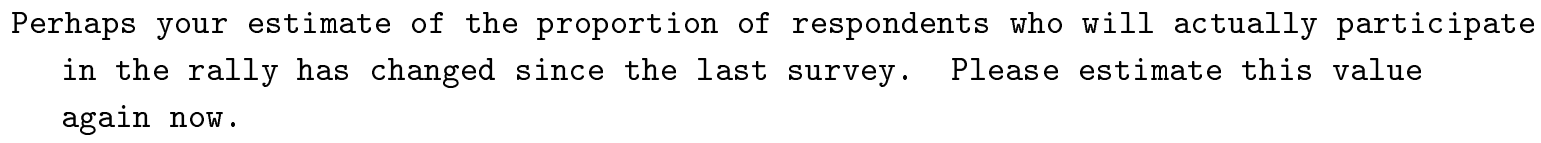

Respondents could type in a number between 0 and 100 with a resolution of a single decimal digit, respectively, which was re-scaled to the unit interval for analysis as variables $\left(b^{\prime}, b\right) \in[0,1]^{2}$. Summary statistics of the empirical distributions at each location and in the pooled sample are listed in Tables 3 and 4 , respectively.

\subsection{Intervention design}

The intervention design is adapted from Cantoni et al. (2019). Two survey instruments relating to intentions to participate in the protest were included in the first questionnaire before the pre-intervention belief $b^{\prime}$ was elicited. They served as inputs for the information treatment given in the second survey. The first was the following simple four-point nominal-scale instrument (Q9 in the questionnaire):

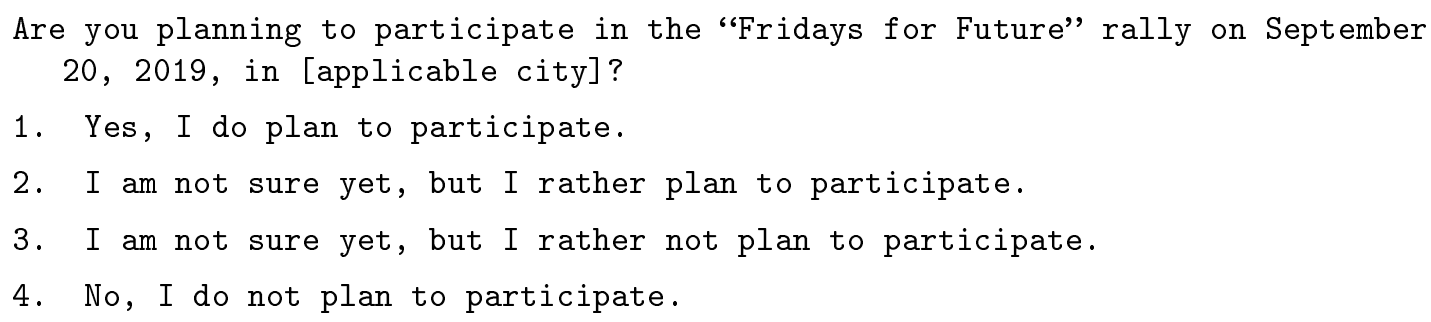

The distribution of responses is shown in the top four rows of Table 5. The fraction of subjects that selected response 1 (intending to participate) or 2 (rather intending to participate), was calculated for each city after the first survey was completed. This variable, denoted $s \in[0,1]$, was accordingly a location-specific constant. The values are shown in the fifth row of Table 5.

The second instrument elicited location-specific beliefs regarding $s(\mathrm{Q} 10$ in the questionnaire):

\footnotetext{
Each survey participant answers the previous question. What do you think - what percentage of all respondents answers the previous question number 9 with "Yes, I do plan to participate" or "I am not sure yet, but I rather plan to participate". There is no right or wrong answer, we are interested in your personal assessment. I estimate that of all survey respondents, --_.- percent answers the previous
} 
Table 4: Summary of post-intervention beliefs regarding others' participation $(b)$ in the climate protest on September 20, 2019.

\begin{tabular}{llllll}
\hline & Berlin & Hamburg & Munich & \multicolumn{1}{l}{ Cologne } & Overall \\
\hline 5-percentile & $.020(.030)$ & $.030(.030)$ & $.030(.030)$ & $.030(.020)$ & $.030(.020)$ \\
25-percentile & $.100(.110)$ & $.100(.100)$ & $.105(.100)$ & $.100(.100)$ & $.100(.100)$ \\
Median & $.235(.250)$ & $.200(.210)$ & $.250(.220)$ & $.230(.230)$ & $.230(.200)$ \\
75 -percentile & $.350(.400)$ & $.350(.367)$ & $.400(.400)$ & $.350(.350)$ & $.350(.400)$ \\
95-percentile & $.650(.660)$ & $.600(.600)$ & $.600(.600)$ & $.600(.600)$ & $.600(.700)$ \\
\hline Mean & $.2647(.2724)$ & $.2568(.2607)$ & $.2587(.2581)$ & $.2556(.2588)$ & $.2594(.2636)$ \\
Standard deviation & $.1982(.2003)$ & $.1784(.1831)$ & $.1768(.1801)$ & $.1845(.1855)$ & $.1860(.1888)$ \\
\hline
\end{tabular}

Table notes: Listed are statistics of the empirical distributions in the final sample (subjects that completed all three surveys, the bottom row of Table 1), with statistics of the distributions in the intermediate second survey sample (including subjects that completed the first two surveys, the middle row of Table 1) in parentheses. Two-sample Kolmogorov-Smirnov tests do not reject equality of distribution functions in the final sample and the class of dropouts in Hamburg $(D=.1109$, exact $p=.343)$, Munich $(D=.0708$, exact $p=.874)$ and Cologne $(D=.0625$, exact $p=.937)$, but in Berlin at a five percent level of significance $(D=.1464$, exact $p=.028)$. A Kruskal-Wallis equality-of-populations rank test does not reject equality of distributions across locations $\left(\chi^{2}(3)=.215\right.$ with ties, $\left.p=.9751\right)$. A Shapiro-Wilk test rejects normality $(z=10.562, p=.0000)$. A maximum likelihood fit to a beta distribition yields a shape parameter estimate of 1.2772 (SEE .0422, $p=.000$ ) and a scale parameter estimate of 3.6295 (SEE .1353, $p=.000$ ) at log $\mathscr{L}=631.82672$, with a one-sample Kolmogorov-Smirnov test again not rejecting equality between the theoretical and empirical distributions $(D=.0538$, $p=.000)$.

question number 9 with "Yes, I do plan to participate" or "I am not sure yet, but I rather plan to participate'.

Again, respondents could type in a number between 0 and 100 at a resolution of a single decimal digit, that was re-scaled to the unit interval for analysis as variable $\tilde{b} \in[0,1]$. Means and standard deviations of the empirical distributions are listed in the bottom row of Table 5.

At the beginning of the second survey, subjects were randomly assigned to either a treatment condition, indicated by $z=1$, or a control condition $(z=0)$. A breakdown of the sample by experimental condition is shown in Table 6. Notably, a two-sided two-sample test of proportions does not reject equality of assignment proportions in the final sample and the class of subjects that dropped out after the second survey (.6795 vs. .6748, $z=-.1723, p=.8632$, see the Table 6 notes for location-specific tests), which supports the assumption that attrition is independent from treatment assignment.

Subjects in the treatment group were informed about their location-specific $s$ before the postintervention belief $b$ was elicited:

The first survey showed that [100.s] percent of all respondents plan or rather plan to participate.

Subjects in the control group did not receive this information (the above sentence was just not displayed). Otherwise the experimental conditions were identical. The idea is that treatment in combination with the reference belief $\tilde{b}$ induces an informational stimulus that gives reason to adjust the post-intervention belief $b$ relative to control. The induced causal effect in beliefs can be exploited to address the problems described at the end of Section 2 and adequately test $\mathrm{H}_{0}$. Details follow in the next section.

Figure 1: Schematic overview of the data generation process.

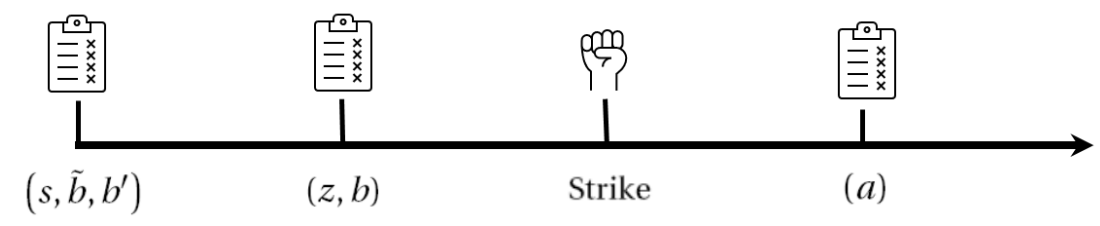


Table 5: Summary of intervention input data: signal values $(s)$ and reference beliefs $(\tilde{b})$.

\begin{tabular}{lrrrrr}
\hline & Berlin & Hamburg & Munich & Cologne & Overall \\
\hline Q9.1 Yes & .0660 & .0707 & .0592 & .0838 & .0699 \\
Q9.2 Rather yes & .2594 & .2965 & .3082 & .2821 & .2832 \\
Q9.3 Rather no & .1946 & .2166 & .2102 & .1641 & .1962 \\
Q9.4 No & .4800 & .4163 & .4224 & .4701 & .4507 \\
\hline$s$ & .325 & .367 & .367 & .366 & $.3324 \pm .2317$ \\
\hline Mean of $\tilde{b}$ & $.3379 \pm .2339$ & $.3315 \pm .2246$ & $.3240 \pm .2295$ & $.3324 \pm .2381$ &. .245 \\
\hline
\end{tabular}

Table notes: The top four rows list the empirical distributions of responses to the participation intention instrument (Q9) in the first survey sample (subjects that completed the first survey, the top row of Table 1) in the form of relative frequencies. A Kruskal-Wallis equality-of-populations rank test does not reject equality of distributions across locations $\left(\chi^{2}(3)=5.926\right.$ with ties, $\left.p=.1153\right)$. The fifth row shows the location-specific signal values $(s)$ calculated from adding the relative frequencies of the first two rows (Q9.1 and Q9.2), respectively. Signal values were shown to treated subjects as a percentage with a single decimal digit. The bottom row lists the means \pm standard deviations of beliefs regarding participation intentions $(\tilde{b})$, elicited by instrument Q10. A Kruskal-Wallis equality-of-populations rank test does not reject equality of distributions across locations $\left(\chi^{2}(3)=1.250\right.$ with ties, $\left.p=.7411\right)$.

Table 6: Sample breakdown by city and experimental condition.

\begin{tabular}{lccccr}
\hline Second survey & Berlin & Hamburg & Munich & Cologne & Overall \\
\hline Control $(z=0)$ & $190(.3115)$ & $162(.3368)$ & $128(.3526)$ & $124(.2918)$ & $604(.3214)$ \\
Treatment $(z=1)$ & $420(.6885)$ & $319(.6632)$ & $235(.6474)$ & $301(.7082)$ & $1,275(.6786)$ \\
\hline Final sample & & & & \\
\hline Control $(z=0)$ & $147(.3000)$ & $134(.3356)$ & $103(.3679)$ & $100(.2933)$ & $484(.3205)$ \\
Treatment $(z=1)$ & $343(.7000)$ & $265(.6642)$ & $177(.6321)$ & $241(.7067)$ & $1,026(.6795)$ \\
\hline
\end{tabular}

Table notes: Listed are the counts of subjects that completed the first two surveys (top panel) or all three surveys (bottom panel) in the respective location class, broken down by experimental condition with column percentages in parentheses. The target treatment assignment probability was two over three. Two-sided binomial probability tests do not reject the null hypothesis that observed assignment (in the final sample) is on target (Berlin: exp. $k=326.67, p=.1251$; Hamburg: exp. $k=266.0, p=.9155$; Munich: exp. $k=186.67, p=.2285$; Cologne: exp. $k=227.33, p=.1211$; Overall: exp. $k=1006.67, p=.2997)$. Two-sided two-sample tests of proportions do not reject equality of assignment proportions in the final sample and the class of dropouts (Berlin: $z=-1.2367, p=.2162$; Hamburg: $z=-.0981, p=.9218$; Munich: $z=1.1162, p=.2643$; Cologne: $z=.1362$ ).

\section{Statistical methods}

The basic statistical approach is to use treatment assignment $(z)$ as an instrumental variable for the potentially endogenous belief variable $b$ (Imbens and Angrist, 1994; Angrist et al., 1996; Clarke and Windmeijer, 2012). By randomization, treatment status is credibly exogenous. Yet, under mild assumptions it affects beliefs, as we demonstrate in section 4.1. We will then continue to specify a generic parametric model that identifies average effect of treatment (ATE) on beliefs. In subsection 4.2 we will connect this model to our probit participation model (1) and show how the treatmentinduced variation in post-intervention beliefs can be exploited to recover the true causal APE and reliably test $\mathrm{H}_{0}$. The direct test of the hypothesis and an indirect test of the key identifying assumptions are specified in Section 4.3.

\subsection{Instrumental belief updating model}

Drawing on the potential outcomes framework (Rubin, 1974, 1990; Holland, 1986), let $b_{z}$ be the potential belief realized under treatment status $z$, such that the (individual) causal effect of treatment is by definition $\tau:=b_{1}-b_{0}$. Given the intervention design described above, this effect will be some function of the stimulus $(s, \tilde{b})$ presented to subjects by treatment. A mild assumption is

$$
\tau=\psi(s-\tilde{b})
$$


with $\psi$ being a monotonically increasing function that goes through the origin. ${ }^{11}$ It reflects the plausible theory that a treated subject with condition $\tilde{b}<s$ learns that actually more people are intending to join the protest than expected, which provides a logical reason for $b_{1}>b_{0}$. The converse logic holds for $\tilde{b}>s$, whereas under condition $\tilde{b}=s$ expectations regarding participation intentions turned out to be accurate, such that there is no reason for $b_{1} \neq b_{0}$.

Depending on treatment assignment, exactly one of the potential post-intervention beliefs is observed for each subject,

$$
b=z \cdot b_{1}+(1-z) \cdot b_{0}=z \cdot \tau+b_{0}
$$

It will be convenient to center the data by defining the change of belief over time relative to the preintervention belief, $\Delta b:=b-b^{\prime}$, such that we observe

$$
\Delta b=z \cdot \tau+\left(b_{0}-b^{\prime}\right)
$$

The latter term in (redundant) parentheses captures any belief adjustment over time that is not controlled by treatment, such as updates reflecting uncontrolled information inflow from other sources. It also has the feature that it is centered about zero, such that $\Delta b>0$ indicates upwards adjustment (expecting others' participation more likely than before), and $\Delta b<0$ indicates downwards adjustment (expecting others' participation less likely than before). This facilitates the joint analysis of all four location strata and already addresses the endogeneity issue to some extent, as pre-intervention beliefs serve as an individual offset.

To account for directional treatment effect heterogeneity implied by (2), define the condition indicator

$$
c= \begin{cases}1 & \tilde{b} \geq s \\ 0 & \tilde{b}<s\end{cases}
$$

such that individuals with a reference belief (at or) above the signal value form the "above group" $(c=1)$, and individuals with a reference belief below signal value form the "below group" $(c=0)$. We can then parametrize the average change of belief conditional on class $c$ and treatment status $z$ by the generalized linear model (GLM)

$$
\mathrm{E}(\Delta b \mid c, z)=L\left(\theta_{0}+\theta_{1} \cdot z+\theta_{2} \cdot c+\theta_{3} \cdot z \cdot c\right)
$$

where $L$ denotes the link function and $\left(\theta_{0}, \theta_{1}, \theta_{2}, \theta_{3}\right) \in \mathbb{R}^{4}$ the estimable parameters of interest. ${ }^{12}$ The parameters $\left(\theta_{0}, \theta_{2}\right)$ can be interpreted as representing systematic inflow of information that is not controlled by treatment, and the error in the latent form of the linear predictor, denoted $e$ for later reference, as representing idiosyncratic inflow of non-controlled information.

The parameters $\left(\theta_{1}, \theta_{3}\right)$ are pivotal for the treatment effect. Specifically, by randomization $z$ will be statistically independent from the potential beliefs $\left(b_{0}, b_{1}\right)$, such that by (3)

$$
\mathrm{E}(b \mid c, z)=\mathrm{E}\left(b_{z} \mid c, z\right)=\mathrm{E}\left(b_{z} \mid c\right)
$$

and in turn, using the definition of $\Delta b$ and the GLM specification (4),

$$
\begin{aligned}
\mathrm{E}\left(b_{1}-b_{0} \mid c\right) & =\mathrm{E}(b \mid c, z=1)-\mathrm{E}(b \mid c, z=0) \\
& =\mathrm{E}(\Delta b \mid c, z=1)-\mathrm{E}(\Delta b \mid c, z=0) \\
& = \begin{cases}L\left(\theta_{0}+\theta_{1}\right)-L\left(\theta_{0}\right) & c=0 \\
L\left(\theta_{0}+\theta_{1}+\theta_{2}+\theta_{3}\right)-L\left(\theta_{0}+\theta_{2}\right) & c=1\end{cases}
\end{aligned}
$$

The left-hand side is the class-specific average treatment effect (ATE), which is by the last equation identified by the predictive margin difference of the fitted model. The monotonicity assumption

\footnotetext{
${ }^{11}$ The monotonicity assumption is actually essential for the instrumental variable approach used in this study (see Imbens and Angrist, 1994; Angrist et al., 1996, and the discussion at the end of the section).

${ }^{12}$ Further conditioning covariates can of course be included (for example location or other fixed effects, which we will do in some specifications considered in section 5.1), but for brevity we will omit them in equation (4).
} 
about $\psi$ implies the hypothesis that the ATE is positive in the "below-group" ( $c=0)$ and negative in the "above-group" $(c=1) .{ }^{13}$ It can be tested by Wald tests applied to the ATE estimates and the delta-method standard errors of estimates, which we will do in Section 5.1.

The GLM model (4) is generally estimable by maximum likelihood estimation methods (MLE, or alternatively Bayesian methods). However, since the results feed as inputs into the estimation of the participation model, due care is needed with respect to specification. We devote attention to two potentially important issues in section 5.1. First, our sample is clustered by location (a subject's home city, there are four possible clusters), date of study enrollment (the date a subject has participated in the first survey, there are six possible days), and date of treatment (the date a subject has participated in the second survey, there are five possible days), and each cluster may have specific effects. We will check for this by means of mixed-effects modeling, allowing for crossed random effects in the three clustering-dimensions. Second, the support of the dependent variable $\Delta b$ is limited to the interval $[-1,1]$. We will check whether estimates from non-linear specifications that take account of this fact differ significantly from linear model estimates. Throughout, we will follow Occam's Razor. It turns out that a simple linear model provides decent results.

\subsection{Augmented participation model}

We augment the participation model (1) in two ways. First, note that it can be expressed equivalently as a function of the change of belief $\Delta b$, as defined above,

$$
\operatorname{Pr}(a=1 \mid \Delta b, \boldsymbol{x})=\Phi(\alpha+\beta \cdot \Delta b+\boldsymbol{x} \cdot \boldsymbol{\gamma})
$$

This changes the interpretation of parameter $\alpha$ and of the predictive margins slightly (the average participation probability if everybody would have the given value of $\Delta b$, averaged over $\boldsymbol{x}$ ), but it is easy to see that the interpretation of $\beta$ and (since $\partial \Delta b / \partial b=1$ ) the marginal effect of beliefs is substantively preserved,

$$
\frac{\partial \operatorname{Pr}(a=1 \mid \Delta b, \boldsymbol{x})}{\partial \Delta b}=\frac{\partial \operatorname{Pr}(a=1 \mid \Delta b, \boldsymbol{x})}{\partial b}=\varphi(\alpha+\beta \cdot \Delta b+\boldsymbol{x} \cdot \boldsymbol{\gamma}) \cdot \beta
$$

such that the meaning of hypothesis $\mathrm{H}_{0}: \beta=0$ is still the same. ${ }^{14}$ Yet, (5) has the advantages described above. ${ }^{15}$

Second, using the belief updating model (4) in conjunction with (5), a control function approach can be used in which the residuals $\hat{e}$ from the belief updating model are employed to fit

$$
\operatorname{Pr}(a=1 \mid \Delta b, \boldsymbol{x}, \hat{\boldsymbol{e}})=\Phi(\alpha+\beta \cdot \Delta b+\eta \cdot \hat{\boldsymbol{e}}+\boldsymbol{x} \cdot \boldsymbol{\gamma})
$$

by MLE, where $\eta \in \mathbb{R}$ is a fixed parameter (Rivers and Vuong, 1988; Blundell and Smith, 1989). ${ }^{16}$ We will report results including location and survey date fixed effects, and with and without bootstrap standard errors that account for clustering by location, date of study enrollment (i .e. date of first survey done), and date of treatment (i. e. date of second survey done). In the Appendix we will also report estimates from a traditional two-step approach in which the belief updating model predictions $\widehat{\Delta b}$ are used to fit

$$
\operatorname{Pr}(a=1 \mid \widehat{\Delta b}, \boldsymbol{x})=\Phi(\alpha+\beta \cdot \widehat{\Delta b}+\boldsymbol{x} \cdot \boldsymbol{\gamma})
$$

\footnotetext{
${ }^{13}$ The former is true if and only if $\theta_{1}>0$, and the latter if and only if $\theta_{1}+\theta_{3}<0$, which jointly implies $\theta_{3}<-\theta_{1}<0$.

${ }^{14}$ To be precise, we will report the APE based on the average structural function (Blundell and Powell, 2004). There are other approaches (Lewbell et al., 2012), but the average structural function approach has decided advantages (Lin and Wooldridge, 2015).

${ }^{15}$ Specifically, Kendall's rank correlation coefficient between $a$ and $b$ is .0884 , and statistically significantly different from zero (tie-corrected Kendall's score $43279 \pm 10576.1$, continuity corrected $p=.0000$ ). Thus, this correlation has the opposite direction of the causal effect that we uncover in Section 5 .

${ }^{16}$ In principle, parameter $\eta$ is estimable and can be used to test for the endogeneity of beliefs, but since MLE estimates the parameters in the belief updating and participation models jointly, it is not actually estimated. Instead a test for zero correlation between the residuals checks for endogeneity (reported in Section 5).
} 
by Newey's efficient minimum $\chi^{2}$ method (Newey, 1987). A key advantage of the control function method is that it estimates the parameters and their variances separately, whereas Newey's estimator yield variance-normalized estimates that are cumbersome to interpret and which cannot directly be compared to the MLE estimates (see Wooldridge, 2010, pp. 585-594, for a detailed discussion).

\subsection{Test of hypothesis and soundness of estimates}

We directly test the null hypothesis $\mathrm{H}_{0}: \beta=0$ against the alternative $\mathrm{H}_{1}: \beta \neq 0$ by a single-parameter Wald test. The square-root of the observed Wald statistic $(\sqrt{W})$ is under the null hypothesis equal to the ratio of the MLE estimate $\hat{\beta}$ and its standard error, and follows an asymptotic normal $(z)$ distribution (Davidson and MacKinnon, 1993, p. 89). We consider the null hypothesis rejected if the observed $\sqrt{W}$ is outside the critical region implied by a false-positive probability threshold (level of significance) of five percent. We will report the $p$-value for easy evaluation under different significance thresholds.

The APE estimate can also be understood within the potential outcomes framework as a so-called local average treatment effect (LATE, Imbens and Angrist, 1994; Angrist et al., 1996). This perspective clarifies that it hinges on two critical assumptions that are fundamentally untestable (because each subject is only observed under one of the two experimental conditions): the independence or valid instrument assumption, and the monotonicity assumption. In our setting the monotonicity assumption means that beliefs follow the direction of the informational stimulus, as formalized by (2), and the valid instrument assumption means that any effect of treatment on participation is fully mediated by beliefs. ${ }^{17}$ Mourifié and Wan (2017) derived testable implications of the two assumptions in the form of two conditional moment inequalities, which can be tested by a conditional likelihood ratio test in the intersection bounds framework (Chernozhukov et al., 2013). We will apply the local method of the test to each of the "above-" and "below-groups" separately, because the monotonicity assumption goes in opposite directions. We consider our estimates as "sound", in the sense of being consistent with the valid instrument and monotonicity assumptions, if none of the tests rejects the null hypothesis that the two conditional moment inequalities are consistent with the data at a significance threshold of no less than ten percent.

\section{Results}

\subsection{Instrumental effect of treatment on beliefs}

Figure 2 visualizes the effect of treatment on beliefs by kernel density plots of observed $\Delta b$ split by experimental condition. As expected, the distribution under treatment is skewed to the right in the "below" group (panel a) and to the left in the "above" group (panel b) relative to control, respectively.

ATE estimates are listed in Tables 7 and 8. The left-hand panel of Table 7 ("Crossed random effects REML") shows the estimates and delta-method SEEs based on the mixed-effects restricted maximum likelihood regression allowing for crossed random effects of location, enrollment date and treatment date with unstructured variances and covariances. ${ }^{18}$ The estimated random effects except the residual are all close to zero, and a likelihood-ratio test rejects the model against a simple fixed effects model ( $p=.9997$ ). Thus, by Occam's Razor, the latter is good enough. Respective ATE estimates and

\footnotetext{
${ }^{17}$ Technically, the latter assumption requires all potential outcomes (potential beliefs and potential participation choices in our setting) to be statistically independent from treatment status, and that treatment has some effect on beliefs in expectation. That this essentially amounts to an exclusion restriction is readily apparent from a causal mediation framework perspective (MacKinnon et al., 2007; Imai et al., 2010; Pearl, 2014; Preacher, 2015): treatment is assumed to have a direct effect on beliefs but no (independent) direct effect on participation, such that the total effect of treatment on participation is purely indirect.

${ }^{18}$ Full estimation results are shown in Table 14 in the Appendix. It also includes the results of a variant that allows for random coefficients at the location level, but like for the random intercepts the respective variances are all close to zero.
} 
Figure 2: Kernel density plots of change in belief $(\Delta b)$ split by experimental condition in the "below" group (a) and the "above" group (b).

(a)

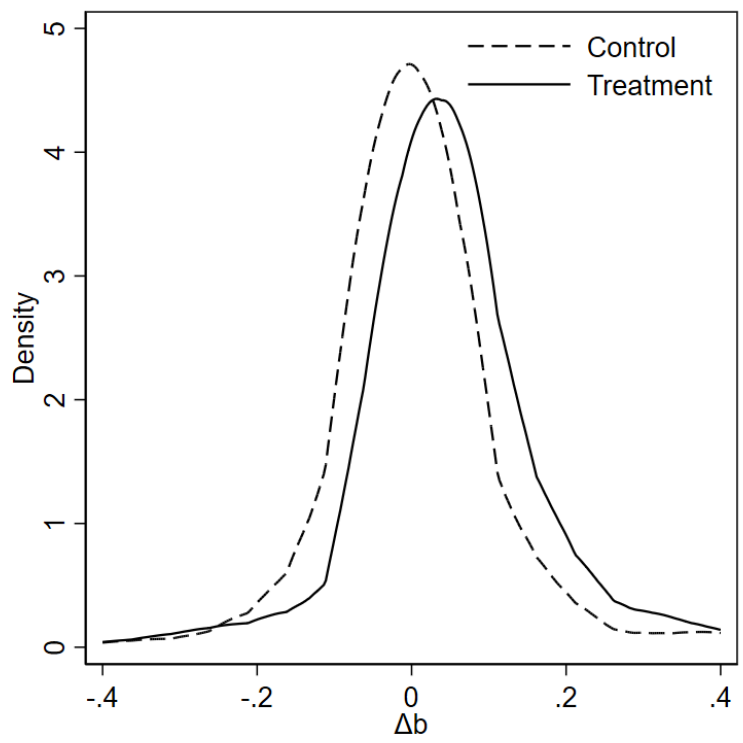

(b)

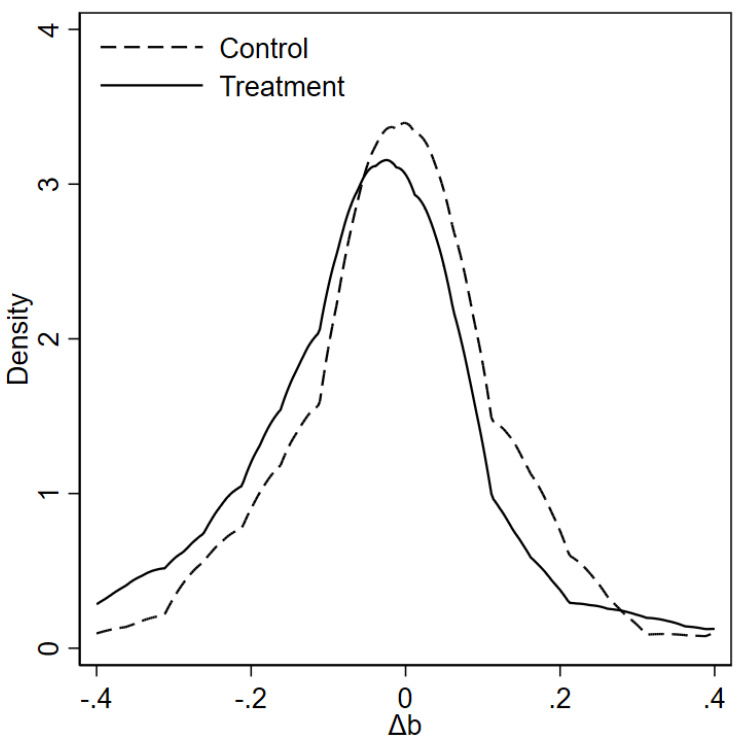

Figure notes: The plots use an Epanechnikov (parabolic) kernel with a 0.05 smoothing parameter. Estimation is restricted to the interval $[-0.4,0.4]$ for brevity, which includes masses .9838 in the "below" group and .9471 in the "above" group.

Table 7: Average treatment effect (ATE) estimates and standard errors of estimates (SEE) based on a linear specification of the belief updating model (4).

\begin{tabular}{lcrlrr}
\hline & \multicolumn{2}{c}{ Crossed random effects REML } & & \multicolumn{2}{c}{ Fixed effects OLS } \\
\cline { 2 - 3 } \cline { 6 - 6 } ATE & Estimate & Delta-SEE $(p)$ & & Estimate & Delta-SEE $(p)$ \\
\hline Below $(c=0)$ & .0425 & $.0097(.000)$ & & .0425 & $.0097(.000)$ \\
Above $(c=1)$ & -.0555 & $.0123(.000)$ & & -.0554 & $.0123(.000)$ \\
\hline
\end{tabular}

Table notes: The estimates and SEEs are based on the regressions reported in tables 14 and 15 in the Appendix. SEEs are derived from the regressions by the delta-method. The $p$-value of a Wald test of the null hypothesis that the ATE estimate is equal to zero is reported in parentheses. Rejections are "highly significant" for $p<.01$, "significant" for $p<.05$, and "marginally significant" for $p<.1$.

delta-method SEEs are shown in the right-hand panel ("Fixed effects OLS") of table $7 .{ }^{19}$ Evidently, the results are almost identical to the left-hand panel.

The constant $\left(\theta_{0}\right)$ is estimated to be not significantly different from zero, such that there is no systematic change of beliefs between the first survey (pre-intervention, $b^{\prime}$ ) and the second survey (postintervention, $b$ ) under control (namely $.243 \pm .009$ vs. $.250 \pm .009$ on average). As expected, treatment causes an upwards adjustment of belief in the average subject belonging to the "below-group", and a downwards adjustment in the "above-group". The magnitudes are 4.2 and 5.5 percentage-points, respectively, and they are clearly different from zero under all conventional significance levels.

Those magnitudes are also robust to non-linear specifications of the belief updating model. Specifically, the ATE estimates shown in table 8 take account of the fact that belief changes are restricted to the interval $[-1,1]$. They are based on fractional probit and beta probit regressions with transforma-

\footnotetext{
${ }^{19}$ Full estimation results are shown in Table 15 in the Appendix. It also reports bootstrap and cluster-bootstrap SEEs with location, enrollment date and treatment date, respectively, defining clusters. Differences to the pooled SEEs are negligible. A specification including location or date fixed effects does produce almost identical results, as all location or date fixed effects are not significantly different from zero. For brevity, those estimates are omitted, but they can be easily replicated with the online materials provided on OSF (Jarke-Neuert et al., 2021).
} 
Table 8: Average treatment effect (ATE) estimates and standard errors of estimates (SEE) based on non-linear specifications of the belief updating model (4) with transformation $2^{-1} \cdot(\Delta b+1)$.

\begin{tabular}{lrrrrr}
\hline & \multicolumn{2}{c}{ Fractional probit } & & \multicolumn{2}{c}{ Beta probit } \\
\cline { 2 - 3 } \cline { 6 - 6 } ATE & Estimate & Delta-SEE $(p)$ & & Estimate & Delta-SEE $(p)$ \\
\hline Below $(c=0)$ & .0212 & $.0037(.000)$ & & .0212 & $.0050(.000)$ \\
Above $(c=1)$ & -.0277 & $.0072(.000)$ & & -.0286 & $.0964(.000)$ \\
\hline
\end{tabular}

Table notes: The estimates and SEEs are based on the regressions reported in tables 16 and 17 in the Appendix. SEEs are derived from the regressions by the delta-method. The $p$-value of a Wald test of the null hypothesis that the ATE estimate is equal to zero is reported in parentheses. Rejections are "highly significant" for $p<.01$, "significant" for $p<.05$, and "marginally significant" for $p<.1$.

Table 9: Predictive margins with standard errors of estimates (SEE) based on maximum likelihood estimation of the augmented probit participation model (6)

\begin{tabular}{lrrrr}
\hline & & \multicolumn{3}{c}{ Delta-SEE $(p$-value $)$} \\
\cline { 2 - 5 } & Estimate & Standard & \multicolumn{1}{c}{ Bootstrap } & Clustered bootstrap \\
\hline Overall & .1099 & $.0080(.000)$ & $.0081(.000)$ & $.0087(.000)$ \\
At means & .0485 & $.0143(.001)$ & $.0156(.002)$ & $.0138(.000)$ \\
\hline At $\Delta b=-.4$ & .5894 & $.1541(.000)$ & $.1620(.000)$ & $.1436(.000)$ \\
At $\Delta b=-.2$ & .3308 & $.0812(.000)$ & $.0849(.000)$ & $.0755(.000)$ \\
At $\Delta b=0$ & .1376 & $.0151(.000)$ & $.0155(.000)$ & $.0151(.000)$ \\
At $\Delta b=.2$ & .0425 & $.0083(.000)$ & $.0089(.000)$ & $.0087(.000)$ \\
At $\Delta b=.4$ & .0103 & $.0048(.032)$ & $.0052(.045)$ & $.0048(.032)$ \\
\hline
\end{tabular}

Table notes: The estimates and SEEs are based on the regressions reported in Table 18. SEEs are derived from the regressions by the delta-method. Bootstrap SEE are based on 1,000 replications, clustered bootstrap SEE allow for correlation of errors within strata formed by crossing locations, enrollment dates, and treatment dates (86 populated clusters). The $p$-value of a Wald test of the null hypothesis that the respective margin estimate is equal to zero is reported in parentheses. Rejections are "highly significant" for $p<.01$, "significant" for $p<.05$, and "marginally significant" for $p<.1$. The mean of $\Delta b$ is equal to .0095397 .

tion $2^{-1} \cdot(\Delta b+1) .^{20}$ The re-transformed estimates are almost identical to the OLS estimates: .0424 for the "below-group" and -.0554 (fractional probit) resp. -.0572 (beta probit) in the "above-group". Again by the principle of parsimony the OLS estimates are good enough.

In sum, the intervention was successful and treatment status is a strong instrument for beliefs in the protest participation model.

\subsection{Average partial effect of a change of belief on participation}

The fitted participation model (6) predicts the observed share of participants in the sample (Table 2) very accurately, as evident from the overall predictive margin estimate in the first row of Table 9 , which is based on the MLE estimation of the augmented participation model (6). ${ }^{21}$ Table 9 also shows the margin at means and the margins at selected fixed values of belief changes $(\Delta b)$. A finer resolution is illustrated in figure 3. A negative relationship between beliefs and the probability of participation is clearly evident.

\footnotetext{
${ }^{20}$ The full estimation results are shown in Tables 16 and 17 in the Appendix. Again, they also report bootstrap-clustered SEEs with location, enrollment date (date of survey 1) and treatment date (date of survey 2), respectively, defining clusters. Differences to the pooled SEEs are still negligible.

${ }^{21}$ The full estimation results are shown in Table 18 in the Appendix. At the local level, the empirical participation share versus specific predictive margin comparisons are .0918 versus .0909 in Berlin, .1128 versus .1126 in Hamburg, .1036 versus .1044 in Munich, and .1378 versus .1386 in Cologne. In the Appendix there are also results obtained via Newey's efficient minimum $\chi^{2}$ two-step method in Table 19. They are almost equal to the MLE estimates, but recall that they are not directly comparable (see section 4 ).
} 
Figure 3: Predictive margins with $95 \%$ confidence intervals at different values of $\Delta b$ based on maximum likelihood estimation of the augmented probit participation model (6)

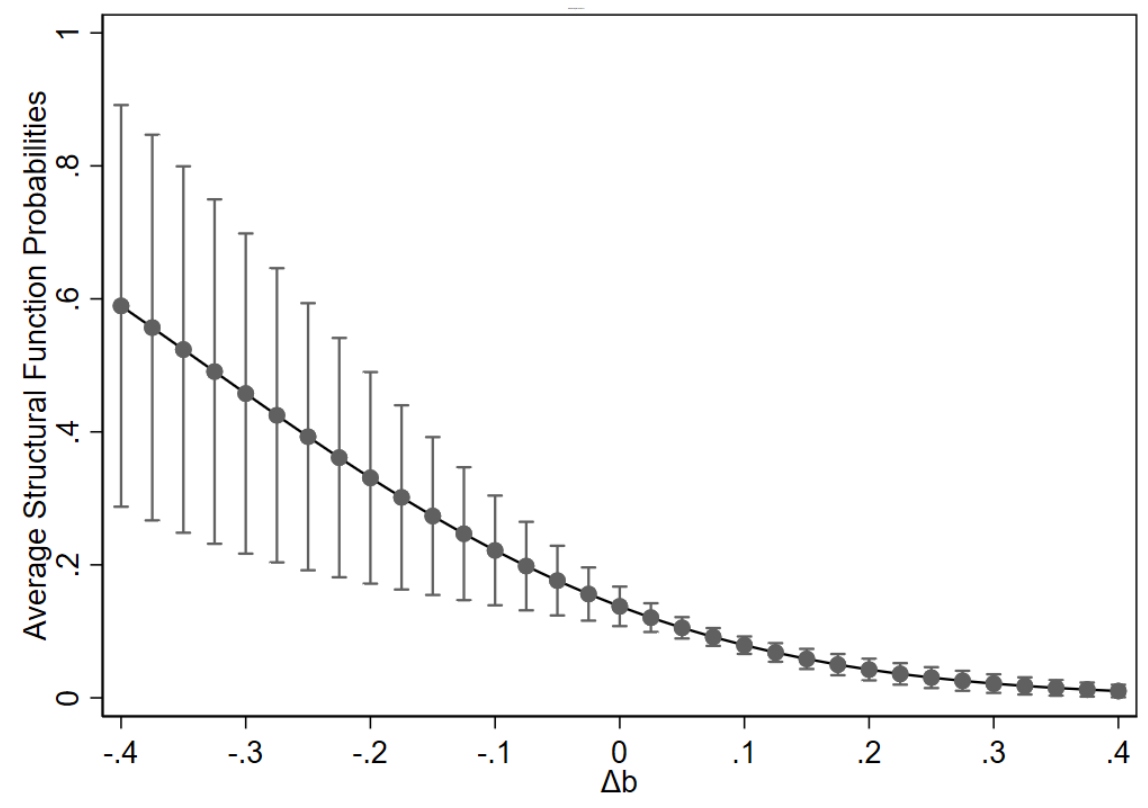

The value of the focal parameter $\beta$ is estimated -3.3062 and with standard errors robustly at around a quarter of that value, such that the Wald test rejects $\mathrm{H}_{0}: \beta=0$ at all conventional levels of significance ( $p=.000$ ). It can be concluded that participation behavior displays strategic substitutability. The APE estimates in Table 10 quantify the magnitude. From the top row of Table 10 we see that overall a one percentage-point increase of belief causes a .67 percentage-point decrease in the probability of participation in the average subject. ${ }^{22}$ The remaining rows also provide estimates of the APE evaluated at the means of all variables, and evaluated at $\Delta b=0$ (i. e. if all subjects would have a post-intervention belief equal to their pre-intervention belief, "at pre.") and at $\Delta b=.0095$, the observed mean ("at post.").

Finally, we turn to the "soundness" of the results as defined in Section 4.3. To begin with, a Wald test against the null hypothesis that $\Delta b$ is exogenous in the standalone model (5) is rejected at all conventional levels of significance with $\chi^{2}(1)=11.62$ and $p=.0007$. Thus, experimental control was in fact crucial for recovering the causal effect of a change in belief on participation. Finally, the conditional likelihood ratio intersection bound tests following the Mourifié-Wan procedure do not reject the joint hypothesis of instrument validity and monotonicity in any of the classes at $p<.1$. We therefore conclude that our results are internally "sound", in the sense that the estimated APE most likely indentifies the causal LATE on the class of subjects that respond to treatment.

\section{Discussion}

This paper connects to several bodies of literature spanning several disciplines. First, it adds to the emerging literature on the structural, tactical, and most importantly (for our purposes) communicational properties of the climate protest movement. Evidence from this line of research shows that the movement is broadly characterized by interpersonally mobilized young females from well-educated backgrounds (Wahlström et al., 2019; de Moor et al., 2020; Hayes and O'Neill, 2021) emphasizing science, peaceful resistance, social and political change, sustainable lifestyle, and inter-generational justice (Holmberg and Alvinius, 2019; Marquardt, 2020; Bugden, 2020; von Zabern and Tulloch, 2021;

\footnotetext{
${ }^{22}$ There is some spatial heterogeneity. The specific overall APE estimates are -.5928 in Berlin, -.6944 in Hamburg, -.6617 in Munich, and -.7978 in Cologne.
} 
Table 10: Average partial effect (APE) estimates with standard errors of estimates (SEE) based on maximum likelihood estimation of the augmented probit participation model (6)

\begin{tabular}{lrrrr}
\hline & & \multicolumn{3}{c}{ Delta-SEE $(p$-value $)$} \\
\cline { 3 - 5 } & Estimate & Standard & \multicolumn{1}{c}{ Bootstrap } & Clustered bootstrap \\
\hline Overall & -.6787 & $.2058(.001)$ & $.2152(.002)$ & $.1918(.000)$ \\
At means & -.3729 & $.0501(.000)$ & $.0501(.000)$ & $.0478(.000)$ \\
At pre. & -.7090 & $.2147(.001)$ & $.2250(.002)$ & $.1999(.000)$ \\
At post. & -.6841 & $.2017(.001)$ & $.2113(.001)$ & $.1877(.000)$ \\
\hline
\end{tabular}

Table notes: The estimates and SEEs are based on the regressions reported in Table 18. SEEs are derived from the regressions by the delta-method. Bootstrap SEE are based on 1,000 replications, clustered bootstrap SEE allow for correlation of errors within strata formed by crossing locations, enrollment dates, and treatment dates (86 populated clusters). The $p$-value of a Wald test of the null hypothesis that the respective ATE estimate is equal to zero is reported in parentheses. Rejections are "highly significant" for $p<.01$, "significant" for $p<.05$, and "marginally significant" for $p<.1$. "At pre." in the third row means the APE evaluated at $\Delta b=0$ (which assumes that all subjects have that value, ceteris paribus), which implies that the post-intervention belief is equal to the pre-intervention belief. Likewise, "At post." in the bottom row means that the APE evaluated at the observed mean of $\Delta b$ (namely .0095397).

Huttunen and Albrecht, 2021), but there seem to be subtle regional differences depending on prevailing political and communicative institutions (Kern and Opitz, 2021). Specifically, social media communication seems to emphasize group cohesion and emotional attachment in some instances (Segerberg and Bennett, 2011; Brünker et al., 2019) and functional information exchange (e. g. documentation and coordination of events, protest tactics, transportation, turnout, police presence, violence, medical services, legal support, etc.) in others (Boulianne et al., 2020). ${ }^{23}$ This is consistent with evidence from several other protest movements summarized in Jost et al. (2018), showing that social media platforms facilitate the exchange of information that is vital to both coordination of protest activities and emotional and motivational contents. This is an interesting complement to our study, as it illustrates the specific mechanisms through which beliefs about turnout are shaped and correlated "in the wild" (i .e. without treatment intervention). That digital communication indeed drives protest dynamics is demonstrated by Enikolopov et al. (2020), who used an instrumental variable approach to recover a causal effect of the penetration of the dominant online social network (VK) on protest activity in 2011 Russia.

Second, we also contribute to a recent stream of literature investigating the motivational (preferences and beliefs) structure underlying climate protest participation. Climate protesters tend to be instrumentally (i. e. to attain a change of public policy) motivated (de Moor et al., 2020; Cologna et al., 2021), although there is regional and individual heterogeneity about advocated means (Beer, 2020; Svensson and Wahlström, 2021; Huttunen, 2021; Soliev et al., 2021), but there is also a strong affectiveemotional basis, revolving around feelings of worry, anxiety, frustration, and anger (Wahlström et al., 2019; de Moor et al., 2020), and a perceived moral duty to act (Fernandes-Jesus et al., 2020; Wallis and Loy, 2021). Social expression and self-signaling, identification, and event enjoyment also play a role (Walgrave et al., 2012; Fernandes-Jesus et al., 2020; Wallis and Loy, 2021; Cologna et al., 2021). ${ }^{24}$ This stream of literature supports our conclusion that both interactive and idiosyncratic factors drive participation decisions. We also believe that the beliefs-preferences-constraints terminology (providing an interface to both decision theoretic analysis and behavioral research) could serve as a powerful framework for organizing extant and further research in this area (see Gintis, 2005, 2014, for a general discussion).

Third, our study also contributes to the rapidly growing empirical literature on protest and social movements more generally, such as the recent social media driven "Occupy" movement (Theocharis

\footnotetext{
${ }^{23}$ Notably, recent evidence suggests that COVID -19 left a footprint in the communication structure by shifting the relative emphasis given to non-functional information (Haßler et al., 2021).

${ }^{24}$ Evidence from two different protest movements in Spain collected by Sabucedo et al. (2017) suggests that concerns of justice are important be for protestors. The inter-generational justice component in climate action suggests that this might also important for climate protesters, at least the young cohorts, but direct evidence on this is lacking.
} 
et al., 2015), "Idle No More" (Raynauld et al., 2017), the "Tea Party" movement (Madestam et al., 2013), "Black Lives Matter" (Freelon et al., 2018), "March for Dignity" (Sabucedo et al., 2017), the "Arab Spring” (Acemoglu et al., 2018), "EuroMaidan" (MacDuffee Metzger and Tucker, 2017), or various youth movements (e. g. Theocharis, 2012; Raynauld and Lalancette, 2016), but also historical cases such as the social movement against slavery in the 19th century US (Dippel and Heblich, 2021). The literature is vast and diverse, a review is beyond the scope of this section (we refer to Jost et al., 2018). But we want to extend on three recent studies that are proximately relevant for us, as they also bear on the strategic component in participation decisions.

The finding of strategic substitutability is consistent with a study very similar to ours in the context of Hong Kong's Umbrella Movement (Cantoni et al., 2019). They used essentially the same informational intervention to induce exogenous variation in survey-measured beliefs within a student sample of potential protesters and also found that an increase of belief concerning others' attendance in a protest reduces the probability of participation. We do not only find similar results in a different protest setting, but extend on their study by providing more statistical power, a heterogenous sample, and a substantially refined econometric framework. The facts that both studies use randomization and control and results go in the same direction can be considered solid evidence in favor of strategic substitutability .

But there is also compelling evidence in favor of strategic complementarity. Manacorda and Tesei (2020) investigate the role of digital information and communication technology in mass political mobilization, using georeferenced data on the coverage of mobile phone signal together with data on protest incidences and individual participation decisions for the entire African continent between 1998 and 2012. They find that mobile phones are instrumental to mass mobilization (only) during economic downturns (when reasons for grievance emerge and the cost of participation falls) in a way being consistent with a network model with imperfect information and strategic complementarities with respect to neighbors' participation. González (2020) studied 2011 high-school student protests for reform of educational institutions in Chile, using administrative data of daily school attendance and an identification strategy exploiting partially overlapping networks and within school exposure to an inaugural college protest. He finds causal evidence of complementarities in school skipping decisions within student networks in national protest days. The mixed evidence suggests that the conditions and determinants of the direction of strategic interdependence seems to be a valuable avenue for further research. ${ }^{25}$

Fourth and finally, our study relates to theoretical work protest movement dynamics, its interface with public policy, and social outcomes. Several recent theoretical studies have furthered traditional analysis of protests movements by considering preferences for fairness and justice (e. g. Passarelli and Tabellini, 2017) and strategic uncertainty (e. g. Bueno de Mesquita, 2010; Shadmehr and Bernhardt, 2011; Edmond, 2013; Shadmehr, 2021). The parametric participation model developed in Jarke-Neuert (2021) and estimated in this paper can capture such aspects parsimoniously, and connects seamlessly with quantal response equilibrium analysis, specifically the class of political participation games (Goeree and Holt, 2005; Goeree et al., 2016). The parameter estimates provide empirically plausible restrictions, and allow for numerically computable simulations. For instance, maximum likelihood fits show that the empirical distributions of beliefs measured in the present study fit nicely to a theoretical beta distribution (see the notes to Tables 3 and 4) with shape parameter about one and scale parameter about three. Drawing on the concept of random beliefs (Sandroni and Smorodinsky, 2004; Friedman and Mezzetti, 2005), the (calibrated) distribution can be used as an empirically plausible seed in game theoretic equilibrium models, or to create pseudo-random draws to equip populations of automata with empirically plausible initial beliefs in simulations.

With an empirically accurate but tractable model of protest dynamics, we believe that a connection to the impressive formal framework recently presented by Egorov and Harstad (2017) could pro-

\footnotetext{
${ }^{25}$ In a within a theoretical model, Shadmehr (2021) shows that when a protest movement's goal is "modest", free-riding concerns dominate making their actions strategic substitutes, whereas when the movement's goal is to overthrow the entire status quo, coordination concerns dominate, and actions become strategic complements. Jarke-Neuert (2021) derives a similar result drawing on step-level public goods terminology.
} 
vide for a powerful "integrated assessment model" for studying the interaction between public regulation, corporate self-regulation and activism, within the realm of climate policy or elsewhere.

\section{Conclusion}

We conclude with a cautious outlook regarding the future of climate protest. The results from our and related studies are mixed news for the movement, as they suggest that the pre-COVID-19 momentum was close to maximum capacity. There is evidence suggesting that the emotional basis of the movement shows signs of erosion (de Moor et al., 2020), and that the COVID-19-related lockdowns may have harmed the momentum persistently (Haßler et al., 2021). Our results suggest that the climate protest movement also not spills over easily from the youth to the adult population, at least in the German sample we studied. Specifically, in equilibrium any exogenous increase (or decrease) in unconditional motivation to join (parameter $\alpha$ in the model) will be (partially) offset by "free-riding" behavior (Jarke-Neuert, 2021).

Nonetheless, it is also possible that some "critical juncture" induces a major turnaround (Capoccia, 2016). Regarding eventual impact of climate protest on actual climate policy, ${ }^{26}$ there is currently no solid evidence. But there are two interesting studies that exemplarily highlight two possible channels and could inspire research in this area. A direct political channel is illustrated by Madestam et al. (2013), who investigate the hen-and-egg problem of whether protests cause political change, or whether they are merely symptoms of underlying shifts in policy preferences. They study the US Tea Party protests on April 15, 2009, exploiting variation in rainfall on that day as an instrumental variable for turnout. They show that good weather had significant consequences for the subsequent local strength of the movement, increased public support for Tea Party positions, and led to more Republican votes in the 2010 midterm elections. Policy making was also affected, as incumbents responded to large protests in their district by voting more conservatively in Congress. Thus, protests can indeed affect policy making.

A more economic channel is suggested by Acemoglu et al. (2018). Using daily variation in the number of participants in street protests that brought down Mubarak's government in Egypt, the authors document that more intense protests are associated with lower stock market valuations for firms connected to the group currently in power relative to non-connected firms, but have no impact on the relative valuations of firms connected to rival groups. This suggests that the protests served as a partial check on political rent-seeking.

\section{References}

Acemoglu, D., Hassan, T. A., and Tahoun, A. (2018). The power of the street: Evidence from Egypt's Arab Spring. Review of Financial Studies, 31:1-42.

Acemoglu, D. and Robinson, J. A. (2006). Economic Origins of Dictatorship and Democracy. Cambridge University Press, New York.

Acemoglu, D. and Robinson, J. A. (2012). Why Nations Fail: The Origins of Power, Prosperity and Poverty. Crown Publishers, New York.

Acemoglu, D. and Robinson, J. A. (2016). Paths to inclusive political institutions. In Eloranta, J., Golson, E., Markevich, A., and Wolf, N., editors, Economic History of Warfare and State Formation, pages 3-50. Springer, Singapore.

Aldy, J. E., Kotchen, M. J., and Leiserowitz, A. A. (2012). Willingness to pay and political support for a US national clean energy standard. Nature Climate Change, 2:596-599.

Almeida, P. D. (2019a). Climate justice and sustained transnational mobilization. Globalization, 16(7):973-979.

Almeida, P. D. (2019b). Social Movements: The Structure of Collective Mobilization. University of California Press, Berkeley.

Amt für Stadtentwicklung und Statistik Köln (2020a). Einwohnerzahlen 2019. Kölner Stadtteilinformationen 2019, Amt für Stadtentwicklung und Statistik Köln, Cologne.

Amt für Stadtentwicklung und Statistik Köln (2020b). Kurzinformation Bevölkerung: 1091819 Kölnerinnen und Kölner im Jahr 2019. Kölner Statistische Nachrichten 3/2020, Amt für Stadtentwicklung und Statistik Köln, Cologne.

\footnotetext{
${ }^{26}$ Generally, and on historical scale, the fate of a protest movement depends on a complex interaction of conditions that are broadly classifiable as institutions and chance (Acemoglu and Robinson, 2012, 2016; Hall and Thelen, 2009).
} 
Amt für Stadtentwicklung und Statistik Köln (2020c). Statistisches Jahrbuch Köln 2019. 96. Jahrgang. Kölner Statistische Nachrichten 1/2020, Amt für Stadtentwicklung und Statistik Köln, Cologne.

Amt für Statistik Berlin-Brandenburg (2020). Einwohnerinnen und Einwohner im Land Berlin am 31. Dezember 2019. Grunddaten. Dritte korrigierte Ausgabe. Statistischer Bericht A I 5 - hj 2 / 19, Amt für Statistik Berlin-Brandenburg, Potsdam.

Andor, M. A., Schmidt, C. M., and Sommer, S. (2019). Climate change, population ageing and public spending: Evidence on individual preferences. Ecological Economics, 151:173-183.

Angrist, J. D., Imbens, G. W., and Rubin, D. B. (1996). Identification of causal effects using instrumental variables. Journal of the American Statistical Association, 91(434):444-455.

Armantier, O. and Treich, N. (2013). Eliciting beliefs: Proper scoring rules, incentives, stakes and hedging. European Economic Review, 62:17-40.

Beckh, P. and Limmer, A. (2022). The Fridays for Future phenomenon. In Wilderer, P. A., Granbow, M., Molls, M., and Oexle, K., editors, Strategies for Sustainability of the Earth System, pages 427-432. Springer, Cham.

Beer, C. T. (2020). "Systems change not climate change": Support for a radical shift away from capitalism at mainstream U.S. climate change protest events. The Sociological Quarterly, 2020:1842141.

Bernauer, T. (2013). Climate change politics. Annual Review of Political Science, 16:421-448.

Blanco, M., Engelmann, D., Koch, A. K., and Normann, H.-T. (2010). Belief elicitation in experiments: Is there a hedging problem? Experimental Economics, 13(4):412-438.

Blasius, J. and Brandt, M. (2010). Representativeness in online surveys through stratified samples. Bulletin of Sociological Methodology, 107(1):5-21.

Blundell, R. W. and Powell, J. L. (2004). Endogeneity in semiparametric binary response models. Review of Economic Studies, 71(3):655-679.

Blundell, R. W. and Smith, R. J. (1989). Estimation in a class of simultaneous equation limited dependent variable models. Review of Economic Studies, 56(1):37-57.

Boulianne, S., Lalancette, M., and Ilkiw, D. (2020). "School strike 4 climate": Social media and the international youth protest on climate change. Media and Communication, 8(2):208-218.

Brannen, S. J., Haig, C. S., and Schmidt, K. (2020). The age of mass protests: Understanding an escalating global trend. Report, Center for Strategic \& International Studies (CSIS), Washington D.C.

Brünker, F., Deitelhoff, F., and Mirbabaie, M. (2019). Collective identity formation on Instagram—Investigating the social movement Fridays for Future. arXiv Preprint 1912.05123, University of Duisburg-Essen.

Bueno de Mesquita, E. (2010). Regime change and revolutionary entrepreneurs. American Political Science Review, 104(3):446-466.

Bugden, D. (2020). Does climate protest work? Partisanship, protest, and sentiment pools. Socius: Sociological Research for a Dynamic World, 6:1-13.

Cantoni, D., Yang, D. Y., Yuchtman, N., and Zhang, Y. J. (2019). Protests as strategic games: Experimental evidence from Hong Kong's antiauthoritarian movement. The Quarterly Journal of Economics, 134(2):1021-1077.

Capoccia, G. (2016). Critical junctures. In Fioretos, K. O., Falleti, T. G., and Sheingate, A. D., editors, The Oxford Handbook of Historical Institutionalism, pages 89-106. Oxford University Press, Oxford.

Chase-Dunn, C. and Almeida, P. D. (2020). Global Struggles and Social Change. Johns Hopkins University Press, Baltimore.

Chernozhukov, V., Lee, S., and Rosen, A. M. (2013). Intersection bounds: Estimation and inference. Econometrica, 81(2):667737.

Clarke, P. S. and Windmeijer, F. (2012). Instrumental variable estimators for binary outcomes. Journal of the American Statistical Association, 107(500):1638-1652.

Cologna, V., Hoogendoorn, G., and Brick, C. (2021). To strike or not to strike? An investigation of the determinants of strike participation at the Fridays for Future climate strikes in Switzerland. PLoS ONE, 16(10):e0257296.

Davidson, R. and MacKinnon, J. (1993). Estimation and Inference in Econometrics. Oxford University Press, New York.

de Moor, J., Uba, K., Wahlström, M., Wennerhag, M., and De Vydt, M. (2020). Protest for a future II: Composition, mobilization and motives of the participants in Fridays For Future climate protests on 20-27 September, 2019, in 19 cities around the world. Report, Stockholm University, Uppsala University, University of Gothenburg, Södertörn University, and University of Antwerp.

Dippel, C. and Heblich, S. (2021). Leadership in social movements: Evidence from the "forty-eighters" in the civil war. American Economic Review, 111(2):472-505.

Edmond, C. (2013). Information manipulation, coordination, and regime change. The Review of Economic Studies, 80(4):1422-1458.

Egorov, G. and Harstad, B. (2017). Private politics and public regulation. The Review of Economic Studies, 84:1652-1682.

Enikolopov, R., Makarin, A., and Petrova, M. (2020). Social media and protest participation: Evidence from Russia. Econometrica, 88(4):1479-1514.

Fernandes-Jesus, M., Lima, M. L., and Sabucedo, J.-M. (2020). "Save the climate! Stop the oil": Actual protest behavior and core framing tasks in the Portuguese climate movement. Journal of Social and Political Psychology, 8(1):426-452.

Flynn, C., Yamasumi, E., Fisher, S., Snow, D., Grant, Z., Kirby, M., Browning, P., Rommerskirchen, M., and Russell, I. (2021). Peoples' Climate Vote. United Nations Development Programme and University of Oxford, New York and Oxford. 
Freelon, D., Marwick, A., and Kreiss, D. (2018). Quantifying the power and consequences of social media protest. New Media \& Society, 20(3):990-1011.

Freelon, D., Marwick, A., and Kreiss, D. (2020). False equivalencies: Online activism from left to right. Science, 369:11971201

Friedman, J. W. and Mezzetti, C. (2005). Random belief equilibrium in normal form games. Games and Economic Behavior, $51(2): 296-323$.

Gächter, S. and Renner, E. (2010). The effects of (incentivized) belief elicitation in public goods experiments. Experimental Economics, 13(3):364-377.

Gifford, R., Kormos, C., and McIntyre, A. (2011). Behavioral dimensions of climate change: Drivers, responses, barriers, and interventions. Wiley Interdisciplinary Reviews: Climate Change, 2(6):801-827.

Gintis, H. (2005). The foundations of behavior: The beliefs, preferences, and constraints model. Biological Theory, 1(2):123127.

Gintis, H. (2014). The Bounds of Reason: Game Theory and the Unification of the Behvioral Sciences. Princeton University Press, Princeton, revised edition.

Goeree, J. K. and Holt, C. A. (2005). An explanation of anomalous behavior in models of political participation. American Political Science Review, 99(2):201-213.

Goeree, J. K., Holt, C. A., and Palfrey, T. R. (2016). Quantal Response Equilibrium: A Stochastic Theory of Games. Princeton University Press, Princeton.

González, F. (2020). Collective action in networks: Evidence from the Chilean student movement. Journal of Public Economics, 188:104220.

Grasso, M. T. (2016). Generations, Political Participation and Social Change in Western Europe. Routledge, London.

Gritz, A. S. (2004). The impact of material incentives on response quantity, response quality, sample composition, survey outcome and cost in online access panels. International Journal of Market Research, 46(3):327-345.

Haßler, J., Wurst, A.-K., Jungblut, M., and Schlosser, K. (2021). Influence of the pandemic lockdown on Fridays for Future's hashtag activism. New Media \& Society, in press.

Hall, P. A. and Thelen, K. (2009). Institutional change in varieties of capitalism. Socio-Economic Review, 7(1):7-34.

Hayes, S. and O'Neill, S. (2021). The Greta effect: Visualising climate protest in uk media and the Getty images collections. Global Environmental Change, 71:102392.

Henry, C., Rockström, J., and Stern, N., editors (2020). Standing Up For A Stustainable World. Edward Elgar, Cheltenham.

Holland, P. W. (1986). Statistics and causal inference. Journal of the American Statistical Association, 81(396):945-960.

Holmberg, A. and Alvinius, A. (2019). Children's protest in relation to the climate emergency: A qualitative study on a new form of resistance promoting political and social change. Childhood, 27(1):78-92.

Huttunen, J. (2021). Young rebels who do not want a revolution: The non-participatory preferences of Fridays for Future activists in Finland. Frontiers in Political Science, 3:672362.

Huttunen, J. and Albrecht, E. (2021). The framing of environmental citizenship and youth participation in the Fridays for Future movement in Finland. Fennia, 199(1):46-60

Imai, K., Keele, L., and Tingley, D. (2010). A general approach to causal mediation analysis. Psychological Methods, 15(4):309-334.

Imbens, G. W. and Angrist, J. D. (1994). Identification and estimation of local average treatment effects. Econometrica, 62(2):467-475

Jarke-Neuert, J. (2021). Playing street politics: A micro-founded parametric and computable model of social mobilization. arxiv preprint, Center for Earth System Research and Sustainability (CEN), University of Hamburg.

Jarke-Neuert, J., Perino, G., and Schwickert, H. (2021). Climate protest is a strategic game: Field experimental evidence from germany-Online materials. Materials pack, Open Science Framework (OSF), DOI 10.17605/OSFIO/Z2EWS.

Jost, J. T., Barberá, P., Bonneau, R., Langer, M., Metzger, M., Nagler, J., Sterling, J., and Tucker, J. A. (2018). How social media facilitates political protest: Information, motivation, and social networks. Political Psychology, 39(51):85-118.

Kamenica, E. (2012). Behavioral economics and psychology of incentives. Annual Review of Economics, 4:427-452.

Kern, T. and Opitz, D. (2021). "Trust science!" institutional conditions of frame resonance in the United States and Germany: The case of Fridays for Future. International Journal of Sociology, 51(3):249-256.

Lewbell, A., Dong, Y., and Yang, T. T. (2012). Comparing features of convenient estimators for binary choice models with endogenous regressors. Canadian Journal of Economics, 45(3):809-829.

Lin, W. and Wooldridge, J. M. (2015). On different approaches to obtaining partial effects in binary response models with endogenous regressors. Economics Letters, 134:58-61.

Liu, P. R. and Raftery, A. E. (2021). Country-based rate of emissions reductions should increase by $80 \%$ beyond nationally determined contributions to meet the $2{ }^{\circ} \mathrm{C}$ target. Communications Earth \& Environment, 2:29.

MacDuffee Metzger, M. and Tucker, J. A. (2017). Social media and EuroMaidan: A review essay. Slavic Review, 76(1):169-191.

MacKinnon, D. P., Fairchild, A. J., and Fritz, M. S. (2007). Mediation analysis. Annual Review of Psychology, 58:593-614.

Madestam, A., Shoag, D., Veuger, S., and Yanagizawa-Drott, D. (2013). Do political protests matter? Evidence from the Tea Party movement. The Quarterly Journal of Economics, 128(4):1633-1685.

Manacorda, M. and Tesei, A. (2020). Liberation technology: Mobile phones and political mobilization in Africa. Economet- 
rica, 88(2):533-567.

Markoff, J. (2014). Waves of Democracy: Social Movements and Political Change. Routledge, New York, 2nd edition.

Marquardt, J. (2020). Fridays for Future's disruptive potential: An inconvenient youth between moderate and radical ideas. Frontiers in Communication, 5:48.

Martin, A. J. (2012). Young People and Politics: Political Engagement in the Anglo-American Democracies. Routledge, New York.

Masson-Delmotte, V., Zhai, P., Pirani, A., Connors, S. L., Péan, C., Berger, S., Caud, N., Chen, Y., Goldfarb, L., Gomis, M. I., Huang, M., Leitzell, K., Lonnoy, E., Matthews, J. B. R., Maycock, T. K., Waterfield, T., Yelekçi, O., Yu, R., and Zhou, B., editors (2021). Climate Change 2021: The Physical Science Basis. Contribution of Working Group I to the Sixth Assessment Report of the Intergovernmental Panel on Climate Change. Cambridge University Press, New York.

Mourifié, I. and Wan, Y. (2017). Testing local average treatment effect assumptions. Review of Economics and Statistics, 99(2):305-313.

Newey, W. K. (1987). Efficient estimation of limited dependent variable models with endogenous explanatory variables. Journal of Econometrics, 36(3):231-250.

Norris, P. (2002). Democratic Pheonix: Reinventing Political Activism. Cambridge University Press, Cambridge.

Passarelli, F. and Tabellini, G. (2017). Emotions and political unrest. Journal of Political Economy, 125(3):903-946.

Pearl, J. (2014). Interpretation and identification of causal mediation. Psychological Methods, 19(4):459-481.

Pickard, S. (2019). Young environmental activists are doing it themselves. Political Insight, 10(4):4-7.

Preacher, K. J. (2015). Advances in mediation analysis: A survey and synthesis of new developments. Annual Review of Psychology, 66:825-852.

Raynauld, V. and Lalancette, Mireille nd Tourigny-Koné, S. (2016). Political protest 2.0: Social media and the 2012 student strike in the province of Quebec, Canada. French Politics, 14:1-29.

Raynauld, V., Richez, E., and Boudreau Morris, K. (2017). Canada is IdleNoMore: Exploring dynamics of Indigenous political and civic protest in the Twitterverse. Information, Communication \& Society, 21(4):626-642.

Rickards, L., Wiseman, J., and Kashima, Y. (2014). Barriers to effective climate change mitigation: the case of senior government and business decision makers. Wiley Interdisciplinary Reviews: Climate Change, 5(6):753-773.

Ripple, W. J., Wolf, C., Newsome, T. M., Gregg, J. W., Lenton, T. M., Palomo, I., Eikelboom, J. A. J., Law, B. E., Huq, S., Duffy, P. B., and Rockström, J. (2021). World scientists' warning of a climate emergency 2021. BioScience, 71(9):894-898.

Rivers, D. and Vuong, Q. H. (1988). Limited information estimators and exogeneity tests for simultaneous probit models. Journal of Econometrics, 39(3):347-366.

Rubin, D. B. (1974). Estimating causal effects of treatments in randomized and nonrandomized studies. Journal of Educational Psychology, 66(5):688-701.

Rubin, D. B. (1990). Formal mode of statistical inference for causal effects. Journal of Statistical Planning and Inference, 25(3):279-292.

Sabucedo, J.-M., Barreto, I., Seoane, G., Alzate, M., Gómez-Román, C., and Vilas, X. (2017). Political protest in times of crisis. construction of new frames of diagnosis and emotional climate. Frontiers in Psychology, 8:1568.

Sandroni, A. and Smorodinsky, R. (2004). Belief-based equilibrium. Games and Economic Behavior, 47(1):157-171.

Schlag, K. H., Tremewan, J., and van der Weele, J. (2015). A penny for your thoughts: A survey of methods for eliciting beliefs. Experimental Economics, 18:457-490.

Segerberg, A. and Bennett, W. L. (2011). Social media and the organization of collective action: Using Twitter to explore the ecologies of two climate change protests. The Communication Review, 14(3):197-215.

Shadmehr, M. (2021). Protest puzzles: Tullock's paradox, hong kong experiment, and the strength of weak states. Quarterly Journal of Political Science, in press.

Shadmehr, M. and Bernhardt, D. (2011). Collective action with uncertain payoffs: coordination, public signals, and punishment dilemmas. American Political Science Review, 105(4):829-851.

Sloam, J. (2013). "Voice and equality": Young people’s politics in the European Union. West European Politics, 36(4):836858.

Sloam, J. (2016). Diversity and voice: The political participation of young people in the European Union. The British Journal of Politics and International Relations, 18(3):521-537.

Sognnaes, I., Gambhir, A., van de Ven, D.-J., Nikas, A., Anger-Kraavi, A., Bui, H., Campagnolo, L., Delpiazzo, E., Doukas, H., Giarola, S., Grant, N., Hawkes, A., Köberle, A. C., Kolpakov, A., Mittal, S., Moreno, J., Perdana, S., Rogeli, J., Vielle, M., , and Peters, G. P. (2021). A multi-model analysis of long-term emissions and warming implications of current mitigation efforts. Nature Climate Change, in press.

Soliev, I., Janssen, M. A., Theesfeld, I., Pritchard, C., Pirscher, F, and Lee, A. (2021). Channeling environmentalism into climate policy: An experimental study of Fridays for Future participants from Germany. Environmental Research Letters, 16(11):114035.

Stammer, D., Engels, A., Marotzke, J., Greese, E., Hedemann, C., and Petzold, J., editors (2021). Hamburg Climate Futures Outlook 2021. Assessing the Plausibility of Deep Decarbonization by 2050. Cluster of Excellence Climate, Climatic Change, and Society (CLICCS), Hamburg.

Statistisches Amt für Hamburg und Schleswig-Holstein (2020). Die Bevölkerung in Hamburg nach Alter und Geschlecht 2019. Endgültige Ergebnisse. Fortschreibung auf Basis des Zensus 2011. Statistischer Bericht A I 3 - j 19 HH, Statistisches 
Amt für Hamburg und Schleswig-Holstein, Hamburg.

Statistisches Amt München (2020a). Bevölkerung am 31.12.2019 nach Alter, Geschlecht und Migrationshintergrund. Statistischer Bericht JT200103, Statistisches Amt München, Munich.

Statistisches Amt München (2020b). Bevölkerung am 31.12.2019 nach Alter und Staatsangehörigkeit in den Stadtbezirken. Statistischer Bericht JT200106, Statistisches Amt München, Munich.

Svensson, A. and Wahlström, M. (2021). Climate change or what? prognostic framing by Fridays for Future protesters. Social Movement Studies, 2021:1988913.

Theocharis, Y. (2012). Cuts, tweets, solidarity and mobilisation: How the internet shaped the student occupations. Parliamentary Affairs, 65(1):162-194.

Theocharis, Y., Lowe, W., van Deth, J. W., and García-Albacete, G. (2015). Using Twitter to mobilize protest action: Online mobilization patterns and action repertoires in the Occupy Wall Street, Indignados, and Aganaktismenoi movements. Information, Communication \& Society, 18(2):202-220.

Tilly, C. (1978). From Mobilization to Revolution. Addison-Wesley, New York.

von Zabern, L. and Tulloch, C. D. (2021). Rebel with a cause: the framing of climate change and intergenerational justice in the german press treatment of the Fridays for Future protests. Media, Culture \& Society, 43(1):23-47.

Wahlström, M., Kocyba, P., De Vydt, M., and de Moor, J. (2019). Protest for a future: Composition, mobilization and motives of the participants in Fridays For Future climate protests on 15 March, 2019, in 13 european cities. Report, University of Gothenburg, Technical University Chemnitz, University of Antwerp, and Stockholm University.

Walgrave, S., Wouters, R., van Laer, J., Verhulst, J., and Ketelaars, P. (2012). Transnational collective identification: May day and climate change protesters' identification with similar protest events in other countries. Mobilization: An International Quarterly, 17(3):301-317.

Wallis, H. and Loy, L. S. (2021). What drives pro-environmental activism of young people? A survey study on the Fridays for Future movement. Journal of Environmental Psychology, 74:101581.

Weibel, P., editor (2015). Global Activism: Art and Conflict in the 21st Century. MIT Press, Cambridge.

Weiss, J. (2020). What is youth political participation? literature review on youth political participation and political attitudes. Frontiers in Political Science, 2:1.

Wooldridge, J. M. (2010). Econometric Analysis of Cross Section and Panel Data. MIT Press, Cambridge, 2nd edition. 
Appendix 
Table 11: Population sizes of Berlin, Hamburg, Munich, and Cologne by the end of 2019, and breakdowns by gender and age.

\begin{tabular}{lrllllllll}
\hline & \multicolumn{2}{c}{ Berlin } & \multicolumn{2}{c}{ Hamburg } & \multicolumn{2}{c}{ Munich } & \multicolumn{2}{c}{ Cologne } \\
\hline Female & $1,904,052$ & $(.5051)$ & 943,279 & $(.5106)$ & 789,041 & $(.5058)$ & 557,563 & $(.5109)$ \\
Male & $1,865,443$ & $(.4949)$ & 903,974 & $(.4894)$ & 771,001 & $(.4942)$ & 534,256 & $(.4895)$ \\
\hline Age <18 & 605,098 & $(.1605)$ & 310,886 & $(.1683)$ & 236,921 & $(.1519)$ & 176,088 & $(.1613)$ \\
Age [18,30[ & 554,064 & $(.1470)$ & 292,351 & $(.1583)$ & 265,629 & $(.1703)$ & 183,968 & $(.1686)$ \\
Age [30,50[ & $1,135,428$ & $(.3012)$ & 542,869 & $(.2939)$ & 499,694 & $(.3203)$ & 323,154 & $(.2961)$ \\
Age [50,65[ & 753,399 & $(.1999)$ & 364,788 & $(.1975)$ & 290,176 & $(.1860)$ & 217,192 & $(.1990)$ \\
Age $\geq 65$ & 721,506 & $(.1914)$ & 336,359 & $(.1821)$ & 267,622 & $(.1715)$ & 191,417 & $(.1754)$ \\
\hline Total & $3,769,495$ & & $1,847,253$ & & $1,560,042$ & & $1,091,819$ & \\
\hline
\end{tabular}

Table notes: Listed are the counts of inhabitants in the respective municipality, broken down by gender and age, with relative class sizes in parentheses. All data are taken from official census records with reporting date December 31, 2019. The raw data source is Amt für Statistik Berlin-Brandenburg (2020) for Berlin, Statistisches Amt für Hamburg und Schleswig-Holstein (2020) for Hamburg, Statistisches Amt München (2020a,b) for Munich, and Amt für Stadtentwicklung und Statistik Köln (2020a,b,c) for Cologne. Own calculations performed where necessary to fit our classification. Specifically for Cologne, a different classification in the 18 up to 65 range is officially reported for the 2019 data (classes 18 up to 25,25 up to 45 , and 45 up to 65), such that we extrapolated the proportions corresponding to our classification (.254 for 18 up to $30, .446$ for 30 up to 50, and .300 for 50 up to 65) from end-of-2018 data (Amt für Stadtentwicklung und Statistik Köln, 2020c) to the total of 724,314 in that class.

Table 12: Sample breakdowns by location, gender and age.

\begin{tabular}{lrlrlrlrlrl}
\hline & \multicolumn{2}{c}{ Berlin } & \multicolumn{2}{c}{ Hamburg } & \multicolumn{2}{c}{ Munich } & \multicolumn{2}{c}{ Cologne } & \multicolumn{2}{c}{ Overall } \\
\hline Female & 261 & $(.5327)$ & 223 & $(.5589)$ & 166 & $(.5929)$ & 188 & $(.5513)$ & 838 & $(.5500)$ \\
Male & 227 & $(.4633)$ & 174 & $(.4361)$ & 114 & $(.4071)$ & 151 & $(.4428)$ & 666 & $(.4411)$ \\
Diverse & 2 & $(.0041)$ & 2 & $(.0050)$ & 0 & $.0000)$ & 0 & $(.0000)$ & 4 & $(.0026)$ \\
No response & 0 & $(.0000)$ & 0 & $(.0000)$ & 0 & $(.0000)$ & 2 & $(.0059)$ & 2 & $(.0013)$ \\
\hline Age less than 18 & 0 & $(.0000)$ & 0 & $(.0000)$ & 0 & $(.0000)$ & 0 & $(.0000)$ & 0 & $(.0000)$ \\
Age 18 up to 30 & 85 & $(.1735)$ & 83 & $(.2080)$ & 65 & $(.2321)$ & 71 & $(.2082)$ & 304 & $(.2013)$ \\
Age 30 up to 50 & 187 & $(.3816)$ & 159 & $(.3985)$ & 120 & $(.4286)$ & 117 & $(.3431)$ & 583 & $(.3861)$ \\
Age 50 up to 65 & 160 & $(.3265)$ & 124 & $(.3108)$ & 76 & $(.2714)$ & 128 & $(.3754)$ & 488 & $(.3232)$ \\
Age 65 and more & 58 & $(.1184)$ & 33 & $(.0827)$ & 19 & $(.0679)$ & 25 & $(.0734)$ & 135 & $(.0894)$ \\
\hline Total & 490 & & 399 & & 280 & & 341 & & 1,510 & \\
\hline
\end{tabular}

Table notes: Listed are the counts of subjects that completed all three surveys in the respective location class, broken down by self-resported gender and age, with relative class sizes in perantheses. A Kruskal-Wallis equality-of-populations rank test does not reject equality of distributions across locations for gender $\left(\chi^{2}(3)=2.790\right.$ with ties, $\left.p=.4252\right)$ but for age at a five-percent level of significance $\left(\chi^{2}(3)=9.487\right.$ with ties, $\left.p=.0235\right)$. This is due to Munich, where the mean ( \pm standard deviation) is lower at $42.42 \pm 14.24$, as compared to Berlin at $45.72 \pm 14.39$, Hamburg at $44.14 \pm 14.44$, and Cologne at $44.54 \pm 14.75$. This corresponds to the overall population properties shown in Table 11, where Munich has a slight bent towards younger ages.

Table 13: Probability-expected sampling frequencies based on the gender and age distributions in the local populations.

\begin{tabular}{lrlrrrrrr}
\hline & \multicolumn{2}{c}{ Berlin } & \multicolumn{2}{c}{ Hamburg } & \multicolumn{2}{c}{ Munich } & \multicolumn{2}{c}{ Cologne } \\
\hline Female & 247.499 & $(.2401)$ & 203.7294 & $(.0057)$ & 141.624 & $(.0040)$ & 174.2169 & $(.1436)$ \\
\hline Age 18 up to 30 & 85.7956 & $(1.000)$ & 75.9246 & $(.3719)$ & 56.2126 & $(.2043)$ & 68.5060 & $(.7355)$ \\
Age 30 up to 50 & 175.8186 & $(.3003)$ & 140.985 & $(.0667)$ & 105.746 & $(.0843)$ & 120.336 & $(.7341)$ \\
Age 50 up to 65 & 116.6622 & $(.0000)$ & 94.7368 & $(.0008)$ & 61.4073 & $(.0428)$ & 80.8780 & $(.0000)$ \\
Age 65 and more & 111.7236 & $(.0000)$ & 87.3536 & $(.0000)$ & 56.6344 & $(.0000)$ & 71.2799 & $(.0000)$ \\
\hline
\end{tabular}

Table notes: Listed are the expected $k$ 's based on the relative frequencies in the overall local populations listed in Table 11 , and the $p$-values of two-sided binomial probability tests of the null hypothesis that the observed $k$ (Table 12) are equal to the expected $k$, respectively, in parentheses. 
Table 14: Restricted maximum likelihood estimates and standard errors of estimates (SEE) of the linear belief updating model (4) with crossed random effects.

\begin{tabular}{|c|c|c|c|c|}
\hline & \multicolumn{2}{|c|}{ with location random slope } & \multicolumn{2}{|c|}{ without location random slope } \\
\hline & Estimate & $\operatorname{SEE}(p)$ & Estimate & $\operatorname{SEE}(p)$ \\
\hline$\theta_{0}$ & .0072 & $.0080(.371)$ & .0072 & $.0080(.371)$ \\
\hline$\theta_{1}$ & .0425 & $.0097(.000)$ & .0425 & $.0097(.000)$ \\
\hline$\theta_{2}$ & -.0003 & $.0132(.982)$ & -.0003 & $.0130(.982)$ \\
\hline$\theta_{3}$ & -.0979 & $.0159(.000)$ & -.0979 & $.0157(.000)$ \\
\hline Log rest. $\mathscr{L}$ & & 835.05084 & & 835.04914 \\
\hline Wald $\chi^{2}(3)$ & & 124.24 & & 124.64 \\
\hline Model $p$ & & .0000 & & .0000 \\
\hline LR test $\chi^{2}(12)$ resp. $\chi^{2}(3)$ & & .01 & & .01 \\
\hline LR test $p$ & & 1.0000 & & .9997 \\
\hline
\end{tabular}

Table notes: Each regression has 1,510 observations. Random intercepts are included at the level of location (four), enrollment date (six), and treatment date (five). The regression in the left-hand panel ("with random slope") also includes random slopes at the location level, the right-hand panel ("without random slope") does not. Variances and covariances are unstructured. All estimated variances and covariances are close to zero $(>-.0001$ and $<.0001)$ except the residual variances, which are .0190 in both models. The two rows at the bottom report the results of a likelihood-ratio test against a simple linear (fixed effects) model. For the standard errors of estimates, the $p$-value of a Wald test of the null hypothesis that the coefficient estimate is equal to zero is reported in parentheses. The bottom row reports the $p$-value of a Wald test against the null hypothesis that all coefficient estimates are jointly zero. Rejections are "highly significant" for $p<.01$, "significant" for $p<.05$, and "marginally significant" for $p<.1$.

Table 15: Ordinary least squares estimates and standard errors of estimates (SEE) of the linear belief updating model (4).

\begin{tabular}{lrrrr}
\hline & & \multicolumn{3}{c}{ SEE $(p$-value $)$} \\
\cline { 3 - 5 } & Estimate & Standard & Bootstrap & Cluster bootstrap \\
\hline$\theta_{0}$ & .0071 & $.0079(.369)$ & $.0058(.218)$ & $.0048(.137)$ \\
$\theta_{1}$ & .0425 & $.0097(.000)$ & $.0074(.000)$ & $.0057(.000)$ \\
$\theta_{2}$ & -.0003 & $.0130(.984)$ & $.0131(.984)$ & $.0117(.982)$ \\
$\theta_{3}$ & -.0979 & $.0157(.000)$ & $.0166(.000)$ & $.0151(.000)$ \\
\hline$F(3,1506)$ & & 41.50 & & 135.43 \\
Wald $\chi^{2}(3)$ & & & 112.36 & .0000 \\
Model $p$ & & .0000 & .0000 & \\
\hline
\end{tabular}

Table notes: Each regression has 1,510 observations, an $R^{2}$ of .0763 , an adjusted $R^{2}$ of .0745 , and a root MSE of .1379. Bootstraps involve 1,000 replications each. There are $4 \times 6 \times 5=120$ feasible clusters of which 86 are populated. A specification including location or date fixed effects does produce almost identical results, as all location or date fixed effects are not significantly different from zero. For the standard errors of estimates, the $p$-value of a Wald test of the null hypothesis that the coefficient estimate is equal to zero is reported in parentheses. The bottom row reports the $p$-value of a Wald test against the null hypothesis that all coefficient estimates are jointly zero. Rejections are "highly significant" for $p<.01$, "significant" for $p<.05$, and "marginally significant" for $p<.1$. 
Table 16: Maximum pseudo-likelihood estimates and standard errors of estimates (SEE) of the non-linear belief updating model (4) in fractional probit regression specification belief with transformation $2^{-1} \cdot(\Delta b+1)$.

\begin{tabular}{lrrrr}
\hline & & \multicolumn{3}{c}{ SEE $(p$-value $)$} \\
\cline { 3 - 5 } & Estimate & Standard & Bootstrap & Cluster bootstrap \\
\hline$\theta_{0}$ & .0089 & $.0072(.216)$ & $.0072(.218)$ & $.0060(.137)$ \\
$\theta_{1}$ & .0533 & $.0093(.000)$ & $.0092(.000)$ & $.0071(.000)$ \\
$\theta_{2}$ & -.0003 & $.0160(.984)$ & $.0164(.984)$ & $.0147(.982)$ \\
$\theta_{3}$ & -.1227 & $.0204(.000)$ & $.0208(.000)$ & $.0189(.000)$ \\
\hline Wald $\chi^{2}(3)$ & & 105.68 & 112.09 & 135.15 \\
Model $p$ & & .0000 & .0000 & .0000 \\
\hline
\end{tabular}

Table notes: Each regression has 1,510 observations, log pseudo- $\mathscr{L}$ of -1045.3992 , and a pseudo- $R^{2}$ of .0011 . Bootstraps involve 1,000 replications each. There are $4 \times 6 \times 5=120$ feasible clusters of which 86 are populated. For the standard errors of estimates, the $p$-value of a Wald test of the null hypothesis that the coefficient estimate is equal to zero is reported in parantheses. The bottom row reports the $p$-value of a Wald test against the null hypothesis that all coefficient estimates are jointly zero. Rejections are "highly significant" for $p<.01$, "significant" for $p<.05$, and "marginally significant" for $p<.1$.

Table 17: Maximum likelihood estimates and standard errors of estimates (SEE) of the non-linear belief updating model (4) in beta probit regression specification with transformation $2^{-1} \cdot(\Delta b+1)$.

\begin{tabular}{lrrrr}
\hline & & \multicolumn{3}{c}{ SEE $(p$-value $)$} \\
\cline { 3 - 5 } & Estimate & Standard & Bootstrap & Cluster bootstrap \\
\hline$\theta_{0}$ & .0092 & $.0103(.368)$ & $.0073(.206)$ & $.0061(.129)$ \\
$\theta_{1}$ & .0532 & $.0125(.000)$ & $.0094(.000)$ & $.0073(.000)$ \\
$\theta_{2}$ & .0010 & $.0168(.954)$ & $.0167(.954)$ & $.0150(.949)$ \\
$\theta_{3}$ & -.1249 & $.0203(.000)$ & $.0217(.000)$ & $.0198(.000)$ \\
\hline Scale & 3.874 & $.0360(.000)$ & $.0814(.000)$ & $.0794(.000)$ \\
\hline Wald $\chi^{2}(3)$ & & 113.54 & 101.68 & 116.39 \\
Model $p$ & & .0000 & .0000 & .0000 \\
\hline
\end{tabular}

Table notes: The link function is probit and the slink function log. Each regression has 1,510 observations and log $\mathscr{L}$ of 1845.9897. Bootstraps involve 1,000 replications each. There are $4 \times 6 \times 5=120$ feasible clusters of which 86 are populated. For the standard errors of estimates, the $p$-value of a Wald test of the null hypothesis that the coefficient estimate is equal to zero is reported in parantheses. The bottom row reports the $p$-value of a Wald test against the null hypothesis that all coefficient estimates are jointly zero. Rejections are "highly significant" for $p<.01$, "significant" for $p<.05$, and "marginally significant" for $p<.1$. 
Table 18: Maximum likelihood estimates and standard errors of estimates (SEE) of the probit participation model (6) including location and survey date fixed effects.

\begin{tabular}{lrrrr}
\hline & & & SEE $(p$-value $)$ \\
\cline { 3 - 5 } & Estimate & Standard & Bootstrap & Cluster bootstrap \\
\hline$\alpha$ & -1.0855 & $.1234(.000)$ & $.1254(.000)$ & $.1413(.000)$ \\
$\beta$ & -3.3062 & $.7984(.000)$ & $.8424(.000)$ & $.7522(.000)$ \\
\hline Hamburg & .1203 & $.1084(.267)$ & $.1104(.276)$ & $.1231(.328)$ \\
Munich & .0827 & $.1224(.499)$ & $.1271(.515)$ & $.1621(.610)$ \\
Cologne & .2485 & $.1108(.025)$ & $.1146(.030)$ & $.1092(.023)$ \\
\hline S1 on Sep 9 & -.0110 & $.0944(.907)$ & $.0947(.907)$ & $.1055(.917)$ \\
S1 on Sep 11 & .0650 & $.1357(.632)$ & $.1471(.659)$ & $.1671(.697)$ \\
S1 on Sep 7 & -.2655 & $.1728(.124)$ & $.1832(.147)$ & $.1465(.070)$ \\
S1 on Sep 6 & -.0052 & $.2259(.982)$ & $.2365(.983)$ & $.2692(.985)$ \\
S1 on Sep 8 & -.2767 & $.3310(.403)$ & $.2649(.296)$ & $.2418(.253)$ \\
\hline S2 on Sep 17 & -.0478 & $.0957(.618)$ & $.0913(.601)$ & $.1156(.679)$ \\
S2 on Sep 16 & -.2168 & $.1209(.073)$ & $.1205(.072)$ & $.1228(.077)$ \\
S2 on Sep 19/20 & -.1817 & $.1720(.291)$ & $.1817(.318)$ & $.1324(.170)$ \\
\hline Corr. of errors & .4519 & .1147 & .1237 & .1091 \\
$\hat{e}$ st. dev. & .1375 & .0025 & .0049 & .0045 \\
\hline Joint Wald $\chi^{2}(12)$ & & 38.39 & 39.95 & 66.33 \\
Joint $p$ & & .0001 & .0001 & .0000 \\
\hline
\end{tabular}

Table notes: Each regression has 1,510 observations and $\log \mathscr{L}=344.82716$. $\Delta b$ is instrumented by $z, c$, and $z \cdot c$. Berlin is the reference category for location. The largest cells (Sep 10 for the first survey, Sep 18 for the second survey) are reference categories for the survey date indicators. The remaining survey date indicators are sorted by cell size with the second-largest cell at the top, respectively. Sep 19 and Sep 20 are merged because the small number of observations at Sep 20 predict success perfectly. A Wald test against the null hypothesis that $\Delta b$ is exogenous (i. e. corr. of errors is zero) is rejected with $\chi^{2}(1)=11.62$ and $p=.0007$. Bootstraps call 1,000 replications each, with only complete ones being used to calculate standard errors (135 replications failed in the pooled specification and 153 in the clustered specification). There are $4 \times 6 \times 5=120$ feasible clusters of which 86 are populated. For the standard errors of estimates, the $p$-value of a Wald test of the null hypothesis that the coefficient estimate is equal to zero is reported in parentheses. The bottom row reports the $p$-value of a Wald test against the null hypothesis that all coefficient estimates are jointly zero. Rejections are "highly significant" for $p<.01$, "significant" for $p<.05$, and "marginally significant" for $p<.1$. 
Table 19: Newey's efficient minimum $\chi^{2}$ estimates and standard errors of estimates (SEE) of the probit participation model (7) including location and survey date fixed effects.

\begin{tabular}{lrrrr}
\hline & & \multicolumn{3}{c}{ SEE $(p$-value $)$} \\
\cline { 3 - 5 } & Estimate & Standard & Bootstrap & Cluster bootstrap \\
\hline$\alpha$ & -1.2163 & $.1165(.000)$ & $.1135(.000)$ & $.1409(.000)$ \\
$\beta$ & -3.6764 & $1.1187(.001)$ & $1.1768(.002)$ & $1.0265(.000)$ \\
\hline Hamburg & .1347 & $.1219(.269)$ & $.1245(.279)$ & $.1369(.325)$ \\
Munich & .0923 & $.1379(.503)$ & $.1444(.523)$ & $.1832(.614)$ \\
Cologne & .2782 & $.1237(.024)$ & $.1276(.029)$ & $.1193(.020)$ \\
\hline S1 on Sep 9 & -.0124 & $.1058(.907)$ & $.1064(.907)$ & $.1177(.916)$ \\
S1 on Sep 11 & .0731 & $.1517(.630)$ & $.1652(.658)$ & $.1867(.695)$ \\
S1 on Sep 7 & -.2973 & $.1925(.123)$ & $.2056(.148)$ & $.1629(.068)$ \\
S1 on Sep 6 & -.0058 & $.2534(.982)$ & $.2680(.983)$ & $.3000(.984)$ \\
S1 on Sep 8 & -.3100 & $.3735(.407)$ & $.2959(.295)$ & $.2696(.250)$ \\
\hline S2 on Sep 17 & -.0535 & $.1072(.618)$ & $.1022(.601)$ & $.1280(.676)$ \\
S2 on Sep 16 & -.2426 & $.1353(.073)$ & $.1354(.073)$ & $.1381(.079)$ \\
S2 on Sep 19/20 & -.2034 & $.1921(.290)$ & $.2037(.318)$ & $.1453(.162)$ \\
\hline Joint Wald $\chi^{2}(12)$ & & 24.33 & 25.33 & 44.27 \\
Joint $p$ & & .0183 & .0133 & .0000 \\
\hline
\end{tabular}

Table notes: Each regression has 1,510 observations. $\Delta b$ is instrumented by $z, c$, and $z \cdot c$. Berlin is the reference category for location. The largest cells (Sep 10 for the first survey, Sep 18 for the second survey) are reference categories for the survey date indicators. The remaining survey date indicators are sorted by cell size with the second-largest cell at the top, respectively. Sep 19 and Sep 20 are merged because the small number of observations at Sep 20 predict success perfectly. A Wald test against the null hypothesis that $\Delta b$ is exogenous (i. e. corr. of errors is zero) is rejected with $\chi^{2}(1)=10.82$ and $p=.0010$. Bootstraps call 1,000 replications each, with only complete ones being used to calculate standard errors (135 replications failed in the pooled specification and 153 in the clustered specification). There are $4 \times 6 \times 5=120$ feasible clusters of which 86 are populated. For the standard errors of estimates, the $p$-value of a Wald test of the null hypothesis that the coefficient estimate is equal to zero is reported in parentheses. The bottom row reports the $p$-value of a Wald test against the null hypothesis that all coefficient estimates are jointly zero. Rejections are "highly significant" for $p<.01$, "significant" for $p<.05$, and "marginally significant" for $p<.1$. 